\title{
Achilles' heel of Iron-Based Catalysts During Oxygen Reduction in Acidic Medium
}

Chang Hyuck Choi, Hyung-Kyu Lim, Gajeon Chon, Min Wook Chung, Abdulrahman Altin, Nastaran Ranjbar Sahraie, Moulay-Tahar Sougrati, Lorenzo Stievano, Hyun Seok Oh, Eun Soo Park, Fang Luo, Peter Strasser, Goran Drazic, Karl J. J. Mayrhofer, Hyungjun Kim, Frederic Jaouen

Submitted date: 22/05/2018 Posted date: 23/05/2018

Licence: CC BY-NC-ND 4.0

Citation information: Choi, Chang Hyuck; Lim, Hyung-Kyu; Chon, Gajeon; Chung, Min Wook; Altin, Abdulrahman; Sahraie, Nastaran Ranjbar; et al. (2018): Achilles' heel of Iron-Based Catalysts During Oxygen Reduction in Acidic Medium. ChemRxiv. Preprint.

Fuel cells efficiently convert chemical into electric energy, with promising application for clean transportation. In proton-exchange membrane fuel cells (PEMFCs), rare platinum metal catalyzes today the oxygen reduction reaction (ORR) while iron(cobalt)-nitrogen-carbon materials $(\mathrm{Fe}(\mathrm{Co})-\mathrm{N}-\mathrm{C})$ are a promising alternative. Their active sites can be classified as atomically dispersed metal-ions coordinated to nitrogen atoms (MeNxCy moieties) or nitrogen functionalities (possibly influenced by sub-surface metallic particles). While their durability is a recognized challenge, its rational improvement is impeded by insufficient understanding of operando degradation mechanisms. Here, we show that FeNxCy moieties in a representative Fe-N-C catalyst are structurally stable but electrochemically unstable when exposed in acidic medium to $\mathrm{H} 2 \mathrm{O} 2$, the main $\mathrm{ORR}$ byproduct. We reveal that exposure to $\mathrm{H} 2 \mathrm{O} 2$ leaves iron-based catalytic sites untouched but decreases their turnover frequency (TOF) via oxidation of the carbon surface, leading to weakened $\mathrm{O} 2$ binding on iron-based sites. Their TOF is recovered upon electrochemical reduction of the carbon surface, demonstrating the proposed deactivation mechanism. Our results reveal a hitherto unsuspected deactivation mechanism during ORR in acidic medium. This study identifies the $\mathrm{N}$-doped carbon surface as Achilles' heel during ORR catalysis in PEMFCs. Observed in acidic but not in alkaline electrolyte, these insights suggest that durable iron-nitrogen-carbon catalysts are within reach for PEMFCs if rational strategies minimizing the amount of $\mathrm{H} 2 \mathrm{O} 2$ or reactive oxygen species (ROS) produced during ORR are developed.

File list (2)

Manuscript_ChemRxiv.pdf (541.15 KiB)

view on ChemRxiv - download file

Supporting Information_ChemRxiv.pdf (1.17 MiB)

view on ChemRxiv - download file 


\section{Achilles' heel of iron-based catalysts during oxygen reduction in}

\section{acidic medium}

Chang Hyuck Choi ${ }^{1 *}$, Hyung-Kyu Lim², Gajeon Chon ${ }^{1}$, Min Wook Chung ${ }^{1}$, Abdulrahman Altin $^{3}$, Nastaran Ranjbar Sahraie ${ }^{4}$, Moulay-Tahar Sougrati ${ }^{4}$, Lorenzo Stievano ${ }^{4}$, Hyun Seok $\mathrm{Oh}^{5}$, Eun Soo Park ${ }^{5}$, Fang Luo ${ }^{6}$, Peter Strasser ${ }^{6}$, Goran Dražić ${ }^{7}$, Karl J. J. Mayrhofer ${ }^{3,8,9}$, Hyungjun $\mathrm{Kim}^{2 *}$ \& Frédéric Jaouen ${ }^{4 *}$

${ }^{1}$ School of Materials Science and Engineering, Gwangju Institute of Science and Technology, 61005 Gwangju, Republic of Korea.

${ }^{2}$ Department of Chemistry, Graduate School of EEWS, Korea Advanced Institute of Science and Technology, 34141 Daejeon, Republic of Korea.

${ }^{3}$ Department of Interface Chemistry and Surface Engineering, Max-Planck Institut für Eisenforschung GmbH, Max-Planck-Str. 1, 40237 Düsseldorf, Germany.

${ }^{4}$ Institut Charles Gerhardt Montpellier, UMR CNRS 5253, Agrégats, Interfaces et Matériaux pour l'Energie, Université de Montpellier, 34095 Montpellier Cedex 5, France.

${ }^{5}$ Department of Materials Science and Engineering, Seoul National University, 08826 Seoul, Republic of Korea.

${ }^{6}$ Department of Chemistry, Chemical Engineering Division, Technical University Berlin, 10623 Berlin, Germany.

${ }^{7}$ Department of Materials Chemistry, National Institute of Chemistry, Hajdrihova 19, 1001 Ljubljana, Slovenia.

${ }^{8}$ Helmholtz-Institute Erlangen-Nürnberg for Renewable Energy (IEK-11), Forschungszentrum Jülich, Egerlandstr. 3, 91058 Erlangen, Germany. 
${ }^{9}$ Department of Chemical and Biological Engineering, Friedrich-Alexander-Universität Erlangen-Nürnberg, Egerlandstr. 3, 91058 Erlangen, Germany.

*Correspondence to: Chang Hyuck Choi (chchoi@gist.ac.kr), Hyungjun Kim (linus16@kaist.ac.kr) or Frédéric Jaouen (frederic.jaouen@umontpellier.fr) 


\section{Introduction}

Fuel cells efficiently convert chemical into electric energy, with promising application for clean transportation. In proton-exchange membrane fuel cells (PEMFCs), rare platinum metal catalyzes today the oxygen reduction reaction $(\mathrm{ORR})^{1}$ while iron(cobalt)-nitrogen-carbon materials $(\mathrm{Fe}(\mathrm{Co})-\mathrm{N}-\mathrm{C})$ are a promising alternative ${ }^{2-5}$. Their active sites can be classified as atomically dispersed metal-ions coordinated to nitrogen atoms $\left(\mathrm{MeN}_{\mathrm{x}} \mathrm{C}_{\mathrm{y}}\right.$ moieties ${ }^{6-9}$ or nitrogen functionalities (possibly influenced by sub-surface metallic particles) ${ }^{10,11}$. While their durability is a recognized challenge, its rational improvement is impeded by insufficient understanding of operando degradation mechanisms ${ }^{12-18}$. Here, we show that $\mathrm{FeN}_{\mathrm{x}} \mathrm{C}_{\mathrm{y}}$ moieties in a representative $\mathrm{Fe}-\mathrm{N}-\mathrm{C}$ catalyst are structurally stable but electrochemically unstable when exposed in acidic medium to $\mathrm{H}_{2} \mathrm{O}_{2}$, the main ORR byproduct. We reveal that exposure to $\mathrm{H}_{2} \mathrm{O}_{2}$ leaves iron-based catalytic sites untouched but decreases their turnover frequency (TOF) via oxidation of the carbon surface, leading to weakened $\mathrm{O}_{2}$ binding on iron-based sites. Their TOF is recovered upon electrochemical reduction of the carbon surface, demonstrating the proposed deactivation mechanism. Our results reveal a hitherto unsuspected deactivation mechanism during ORR in acidic medium. This study identifies the N-doped carbon surface as Achilles' heel during ORR catalysis in PEMFCs. Observed in acidic but not in alkaline electrolyte, these insights suggest that durable iron-nitrogen-carbon catalysts are within reach for PEMFCs if rational strategies minimizing the amount of $\mathrm{H}_{2} \mathrm{O}_{2}$ or reactive oxygen species (ROS) produced during ORR are developed. 


\section{Results and discussion}

A representative Fe-N-C catalyst was selected (labelled FeNC-1), comprising Fe mainly as metal ions atomically dispersed as $\mathrm{FeN}_{\mathrm{x}} \mathrm{C}_{\mathrm{y}}$ moieties (Fig. S1 and Table S1). These moieties are ubiquitous in Fe-N-C materials that efficiently catalyze ORR in acidic medium ${ }^{7,8,13-16}$. From surface-specific CO-chemisorption ${ }^{19}$ and bulk Fe-content measurements, we determined that $\geq 20 \%$ of all Fe atoms in FeNC-1 are on the surface (Fig. S1d, e). We previously demonstrated in acidic electrolyte that FeNC-1 fully retained its ORR activity after extensive cycling from 0.0 to $1.0 \mathrm{~V}_{\mathrm{RHE}}{ }^{16}$, and that $\mathrm{FeN}_{\mathrm{x}} \mathrm{C}_{\mathrm{y}}$ moieties did not leach out during electrochemical cycling ${ }^{15}$. In spite of this, FeNC-1 shows a continuous deactivation during steady-state operation in $\mathrm{PEMFCs}^{15}$, a conundrum impeding the rational development of stable $\mathrm{Fe}-\mathrm{N}-\mathrm{C}$ cathodes. Partially unveiling this conundrum, $\mathrm{H}_{2} \mathrm{O}_{2}$ was shown to chemically react with $\mathrm{Fe}-\mathrm{N}-\mathrm{C}^{14}$, decreasing its ORR activity, however via an unexplained mechanism. Here, we reveal the detailed deactivation mechanism by $\mathrm{H}_{2} \mathrm{O}_{2}$.

The ORR activity and selectivity of pristine FeNC-1 were measured in acidic and alkaline electrolytes. FeNC-1 shows a higher ORR activity in alkaline than acidic medium (Fig. 1a, b and Fig. S2), typical for Fe-N-C materials ${ }^{20}$. Less than $5 \%$ hydrogen peroxide is detected above $0.3 \mathrm{~V}_{\text {RHE }}$ during ORR in both electrolytes (Fig. 1c, d). Changes in activity and selectivity induced by $\mathrm{H}_{2} \mathrm{O}_{2}$-treatments were then investigated. The catalytic layer comprising FeNC-1 and Nafion ${ }^{\circledR}$ ionomer was immersed in a $5 \mathrm{wt} \% \mathrm{H}_{2} \mathrm{O}_{2}$ solution of $\mathrm{pH} 1$ at 20 (label FeNC-120), 50 or $70{ }^{\circ} \mathrm{C}$. The ORR activity of $\mathrm{H}_{2} \mathrm{O}_{2}$-treated FeNC-1 electrodes was then measured either in $0.1 \mathrm{M} \mathrm{HClO}_{4}$ or $\mathrm{KOH}$. During this treatment, $\mathrm{H}_{2} \mathrm{O}_{2}$ is the sole deactivating agent, a pH 1 solution without $\mathrm{H}_{2} \mathrm{O}_{2}$ not impacting the activity ${ }^{15}$. As seen in Fig. 1a, the ORR activity measured at $\mathrm{pH} 1$ after the acidic $\mathrm{H}_{2} \mathrm{O}_{2}$-treatment decreases with increasing treatment 
temperature. This drop is independent of the electrochemical potential applied to FeNC-1 during $\mathrm{H}_{2} \mathrm{O}_{2}$-treatment (Fig. S3a-c), indicating that chemical reactions between FeNC-1 and $\mathrm{H}_{2} \mathrm{O}_{2}$ must account for the activity decay. The ORR rate-determining step (RDS) is however unchanged, as revealed by similar Tafel slope (TS) of $63-67 \mathrm{mV} \mathrm{dec}^{-1}$, except after the $70{ }^{\circ} \mathrm{C}$ $\mathrm{H}_{2} \mathrm{O}_{2}$-treatment, for which the TS-value is $110 \mathrm{mV} \mathrm{dec}^{-1}$ (Fig. 1a). The increase from 63 to $110 \mathrm{mV} \mathrm{dec}^{-1}$ might be interpreted as the RDS changing from a chemical step between the first and second electron transfer (ET) to the first ET (Fig. S4a). Regarding selectivity, increased temperature during $\mathrm{H}_{2} \mathrm{O}_{2}$-treatment continuously increases the amount of $\mathrm{H}_{2} \mathrm{O}_{2}$ released during ORR from 4 to $29 \%$ at $0.5 \mathrm{~V}_{\text {RHE }}$ (Fig. 1c). Similar trends are observed for ORR activity and selectivity in alkaline electrolyte, following acidic $\mathrm{H}_{2} \mathrm{O}_{2}$-treatments (Fig. 1b, d). In contrast, peroxide-treatment in $0.1 \mathrm{M} \mathrm{KOH}$ did not modify the ORR activity nor selectivity of FeNC-1, measured either in $0.1 \mathrm{M} \mathrm{HClO}_{4}$ or $\mathrm{KOH}$ (Fig. S3g, h). This strongly suggests that ROS formation from peroxide and $\mathrm{Fe}-\mathrm{N}-\mathrm{C}$ is $\mathrm{pH}$-dependent, in line with the acidic $\mathrm{pH}$-range chosen for producing ROS from $\mathrm{H}_{2} \mathrm{O}_{2}$ and $\mathrm{Fe}$ cations in the frame of environmental water remediation ${ }^{21}$. To demonstrate that ROS species formed during the acidic $\mathrm{H}_{2} \mathrm{O}_{2}$ treatment of Fe-N-C, we used a nitrone spin-trap (5,5-dimethyl-1-pyrroline N-oxide, DMPO) and electron paramagnetic resonance (EPR). EPR spectra of filtered solution aliquots collected after 5 min of reaction between FeNC-0.5 (prepared as FeNC-1 but with halved Fe content, comprising only $\mathrm{FeN}_{\mathrm{x}} \mathrm{C}_{\mathrm{y}}$ moieties, see later) and $\mathrm{H}_{2} \mathrm{O}_{2}$ in DMPO identify the presence of a main signal that can be unambiguously assigned to the $\mathrm{DMPO}-\mathrm{OH}$ spin adduct (quartet signal with $1: 2: 2: 1$ intensity ratio), observed in $\mathrm{pH} 1$ but not in $\mathrm{pH} 13$ conditions (Fig. S5). Other ROS than hydroxyl radicals may however have been be produced during the peroxide treatment of FeNC0.5, since other DMPO-ROS adducts than DMPO-OH have a shorter lifetime and quickly 
breakdown to DMPO-OH adducts. In summary, the spin-trap experiments further support ROS formation only in acidic environment, not in alkaline environment.

The structure and chemistry of acidic $\mathrm{H}_{2} \mathrm{O}_{2}$-treated catalysts were then investigated. As reported by us for another $\mathrm{H}_{2} \mathrm{O}_{2}$ protocol ${ }^{14}$, the Fe K-edge extended X-ray absorption fine structure (EXAFS) spectra are unmodified by $\mathrm{H}_{2} \mathrm{O}_{2}$-treatments, indicating unmodified firstcoordination sphere in $\mathrm{FeN}_{\mathrm{x}} \mathrm{C}_{\mathrm{y}}$ moieties (Fig. 2a). EXAFS is however poorly sensitive to the second coordination sphere of $\mathrm{FeN}_{\mathrm{x}} \mathrm{C}_{\mathrm{y}}$ moieties $^{8}$. Mössbauer spectroscopy is more sensitive to both coordination and electron population at ${ }^{57} \mathrm{Fe}$ nuclei. The doublets D1 and D2 observed in pristine FeNC-1 (Fig. S1b) and FeNC-0.5 (prepared as FeNC-1 but with halved Fe content) are still present in $\mathrm{H}_{2} \mathrm{O}_{2}$-treated samples (Fig. S6) but the spectra have a slightly modified shape and intensity. They were analysed assuming Gaussian distributions of the quadrupole splitting (QS), justified by the structural disorder revealed by transmission electron microscopy on FeNC-1 (Fig. S1f). Such an approach reveals highest QS-probabilities in FeNC-0.5 (Fig. 2b) at the values found for doublets D1-D2 (Table S1). With increasing $\mathrm{H}_{2} \mathrm{O}_{2}$-treatment temperature, the low-QS relative intensity decreases and the distribution at high-QS is slightly modified. Such minor changes comply with modifications of the second coordination sphere in $\mathrm{FeN}_{\mathrm{x}} \mathrm{C}_{\mathrm{y}}$ moieties, but with an intact $\mathrm{FeN}_{4}$ core. Other possible chemical changes were investigated by X-ray photoelectron spectroscopy (XPS) and elemental analysis. The $\mathrm{N}_{1 \mathrm{~s}}$ signal was almost unmodified after $\mathrm{H}_{2} \mathrm{O}_{2}$-treatments (Fig. 2c, Fig. S7a-d), indicating no oxidation of $\mathrm{N}$-functionalities, including those ligating Fe. The total $\mathrm{Fe}$ and $\mathrm{N}$ contents were also unchanged after $\mathrm{H}_{2} \mathrm{O}_{2}$-treatment (Fig. 2e). The pore size distribution, specific surface area and bulk carbon structure of $\mathrm{H}_{2} \mathrm{O}_{2}$-treated catalysts were identical to those of FeNC-1, as revealed by $\mathrm{N}_{2}$ physisorption (Fig. 2f) and Raman spectroscopy (not shown). The lack of modifications is 
apparently contentious with decreased activity and selectivity. An important exception is the oxygen content, increasing from 5 to 10 at\% (Fig. 2e). The $\mathrm{O}_{1 \mathrm{~s}}$ signal (Fig. 2d) reveals a broad peak that was fitted with $\mathrm{C}=\mathrm{O}$ (carbonyl, carboxyl) and $\mathrm{C}-\mathrm{O}$ (epoxy, hydroxyl) components (Fig. S7e-h). An interesting analogy can be drawn between the oxidation process of FeNC-1 by $\mathrm{H}_{2} \mathrm{O}_{2}$ and the formation of graphene oxide (GO) from graphite, $\mathrm{H}_{2} \mathrm{O}_{2}$ and potassium ferrate ${ }^{22}$.

These results suggest that carbon oxidation was restricted to the top-surface (without formation of volatile $\mathrm{CO}$ or $\mathrm{CO}_{2}$ products), the acidic $\mathrm{H}_{2} \mathrm{O}_{2}$-treatment selectively oxidizing a fraction of surface carbon atoms via Fenton-like reactions with $\mathrm{FeN}_{\mathrm{x}} \mathrm{C}_{\mathrm{y}}$ surface moieties. This might have induced a lower ORR-TOF on otherwise unmodified $\mathrm{FeN}_{\mathrm{x}} \mathrm{C}_{\mathrm{y}}$ moieties. If this is true, the ORRactivity decrease consequential to the $\mathrm{H}_{2} \mathrm{O}_{2}$-treatment should be recovered when the carbon surface is cleaned from oxygen functionalities. We opted for electrochemical reduction to softly remove oxygen groups, a method reported for GO reduction ${ }^{23}$. Fig. 1e, f show that the ORR activity and selectivity in acidic medium of the $\mathrm{H}_{2} \mathrm{O}_{2}$-treated materials significantly increased after electro-reduction in $0.5 \mathrm{M} \mathrm{NaCl}$ (e.g. activity x3.2 for reduced FeNC-1-50). The extent of activity recovery is high for FeNC-1-20 and FeNC-1-50 (67-82 \% relative to FeNC-1 activity at $\left.0.8 \mathrm{~V}_{\mathrm{RHE}}\right)$. Activity and selectivity recovery is however not complete, and this is amplified with highly-oxidized FeNC-1-70. This may be due to incomplete removal of oxygen groups formed during $\mathrm{H}_{2} \mathrm{O}_{2}$-treatment, especially epoxy groups as reported for electrochemically-reduced $\mathrm{GO}^{23}$. The possible role of metallic Fe particles in FeNC-1 on either the deactivation or activity recovery could be excluded by investigating FeNC-0.5, comprising only $\mathrm{FeN}_{\mathrm{x}} \mathrm{C}_{\mathrm{y}}$ moieties (Fig. S6) ${ }^{8}$. Its ORR deactivation after $\mathrm{H}_{2} \mathrm{O}_{2}$-treatment and recovery after electro-reduction are identical to those of FeNC-1 (Fig. S3i). 
We resorted to density functional theory (DFT) to understand how carbon surface oxidation modifies the TOF and selectivity of $\mathrm{FeN}_{\mathrm{x}} \mathrm{C}_{\mathrm{y}}$ moieties. The $\mathrm{O}_{2}$-binding energy $\left(E_{\mathrm{b}}\right)$ on $\mathrm{FeN}_{4}$ centers, a key descriptor of ORR activity ${ }^{24}$, and electron work function (WF) of the surface were calculated against the type, number and location of oxygen groups near $\mathrm{FeN}_{\mathrm{x}} \mathrm{C}_{\mathrm{y}}$ moieties (Fig. S8a). The introduction of hydroxyl and especially epoxy groups in the basal plane dramatically modifies $E_{\mathrm{b}}$ from -0.59 to $+0.33 \mathrm{eV}$ (Fig. 3a), a conclusion valid for all oxygen adsorbates (Fig. S8b). As previously discussed by Mukerjee's group ${ }^{6}$, electron-withdrawing groups on the carbon surface not only downshift the iron $d$-orbitals (Fig. S9), thereby decreasing iron oxophilicity (Fig. 3b), but also deplete the carbon support from $\pi$-electrons, thereby elevating the WF (Fig. 3a). Weakened $E_{\mathrm{b}}$ decreases the activity of FeNC-1, implying that $\mathrm{FeN}_{4}$ centers integrated in graphene sheets are located either near the apex or on the weakbinding side of an activity vs. binding-energy volcano plot.

Selectivity toward four-electron reduction was also investigated with DFT considering the ORR mechanism detailed in Fig. 3c. The first ET results in an iron-hydroperoxo complex (step 2). If the subsequent $\mathrm{O}-\mathrm{OH}$ bond cleavage and second ET occurred in a concerted step at a single $\mathrm{FeN}_{\mathrm{x}} \mathrm{C}_{\mathrm{y}}$ moiety (step 3 ), a considerable reorganization energy would be expected ${ }^{25}$. Instead, we consider an $\mathrm{O}-\mathrm{O}$ bond cleavage assisted by the nearest carbon atom, situated only $2.67 \AA$ away from $\mathrm{Fe}$ (step 4, Fig. S4b), defining a cooperative OOH dissociation pathway ${ }^{26}$. This pathway becomes less favorable with surface oxidation (electronic effect) and could even be sterically blocked if the cooperative carbon center is occupied by an oxygen group, favoring $\mathrm{H}_{2} \mathrm{O}_{2}$ formation (Fig. S10a). Furthermore, N-doped graphene has stronger affinity to oxygen groups than graphene, inferring that surface oxidation might occur preferentially on carbons adjacent to nitrogen atoms (Fig. S10b). 
Following these DFT insights, we measured WF, potential of zero charge $\left(E_{\mathrm{PZC}}\right)$ and basicity of $\mathrm{H}_{2} \mathrm{O}_{2}$-treated FeNC-1. Ultraviolet photoelectron spectroscopy indicates increased WF with acidic $\mathrm{H}_{2} \mathrm{O}_{2}$-treatment, leading to a negative correlation between ORR activity and WF (Fig. 4a-c). This is consistent with our DFT calculations (Fig. 3a) and recent studies on the initial ORR activity of Fe-N-C and N-S-O-C materials ${ }^{27,28} . E_{\mathrm{PZC}}$ is also negatively correlated with ORR activity (Fig. 4d-f). The surface basicity, $\mathrm{pH}_{\mathrm{f}}$, decreased with increasing $\mathrm{H}_{2} \mathrm{O}_{2}$-treatment temperature due to the acidic character of oxygen groups, leading to a positive correlation with ORR activity (Fig. 4g-i). These correlations are explained on the basis of a modulation of the TOF of $\mathrm{FeN}_{\mathrm{x}} \mathrm{C}_{\mathrm{y}}$ moieties by the electronic properties of the surrounding carbon surface. This concept bears similarities with the importance of solid-state physics for electrochemical reaction rates, demonstrated in the 1970's for metallic surfaces ${ }^{29}$. In practice, in addition to decreasing the TOF of $\mathrm{FeN}_{\mathrm{x}} \mathrm{C}_{\mathrm{y}}$ moieties via carbon surface oxidation, peroxide or ROS formed during PEMFC operation might also increase the catalyst's hydrophilicity and attack the proton-conductive ionomer. Both phenomena could lead to decreased transport properties through the cathode, possibly further amplifying the performance loss. For FeNC-1 however, our previous study showed that only the ORR activity significantly decreased during PEMFC operation $^{14}$.

\section{Conclusion}

In summary, we explain the main deactivation of Fe-N-C catalysts for ORR in PEMFCs as a reversible surface oxidation of carbon, decreasing the TOF of Fe-based active sites via weakened $\mathrm{O}_{2}$ binding. This study provides novel insights into the operando deactivation of $\mathrm{Fe}-$ $\mathrm{N}-\mathrm{C}$ catalysts comprising $\mathrm{FeN}_{\mathrm{x}} \mathrm{C}_{\mathrm{y}}$ sites. While Fe-N-C catalysts comprising only Fe particles 
encapsulated in a graphitic shell might not experience this deactivation (no surface iron), the ORR activity of such catalysts has hitherto been $\operatorname{low}^{30}$. The need to consider $\mathrm{FeN}_{\mathrm{x}} \mathrm{C}_{\mathrm{y}}$ moieties in their long-range electronic and chemical environment for TOF determination and the recoverable decay of TOF are important paradigm shifts. The present study brings hope for durable Fe-N-C cathodes in high power density PEMFCs, with in situ (electro)reduction of carbon, $\mathrm{H}_{2} \mathrm{O}_{2}$ or radical scavengers. 


\section{Data availability}

All data are available from the corresponding authors upon reasonable request.

\section{Acknowledgements}

The research leading to these results was supported by ANR under contract 2011 CHEX 004 01, by Creative Materials Discovery Program through the National Research Foundation of Korea (NRF) funded by Ministry of Science and ICT (NRF-2017M3D1A1039376) and by the European Union's Horizon 2020 research and innovation programme under grant agreement CREATE No. 721065. C.H.C. acknowledges the support by the National Research Foundation of Korea (NRF) grant funded by the Korea government (MSIP) (NRF-2017R1C1B2002918). P.S. acknowledges support by the European Commission, H2020, Fuel Cell Hydrogen Joint Undertaking (FCH-JU 2) programs.

\section{Author contributions}

C.H.C., H.K. and F.J. designed the research. G.C. and M.W.C. performed electrochemical studies. A.A., N.R.-S., M.T.S., L.S., H.S.O., E.S.P., F.L. and G.D. performed spectroscopic and other characterization measurements and analysed the data. H.-K.L. and H.K. performed computational calculations. P.S. and K.J.J.M. provided instrumental support and critical advises. C.H.C., H.K. and F.J. wrote the manuscript with comments from all authors.

\section{Author information}

Reprints and permissions information is available at www.nature.com/reprints. The authors declare no competing financial interests. Correspondence and requests for materials should be addressed to F.J. (frederic.jaouen@umontpellier.fr), H.K. (linus16@kaist.ac.kr) or C.H.C. (chchoi@gist.ac.kr). 


\section{References}

1 Debe, M. K. Electrocatalyst approaches and challenges for automotive fuel cell s. Nature 486, 43-51 (2012).

2 Lefèvre, M., Proietti, E., Jaouen, F. \& Dodelet, J. P. Iron-based catalysts with improved oxygen reduction activity in polymer electrolyte fuel cells. Science 32 4, 71-74 (2009).

3 Wu, G., More, K. L., Johnston, C. M. \& Zelenay, P. High-performance electro catalysts for oxygen reduction derived from polyaniline, iron, and cobalt. Scien ce 332, 443-447 (2011).

4 Li, Y. et al. An oxygen reduction electrocatalyst based on carbon nanotube-gra phene complexes. Nat. Nanotechnol. 7, 394-400 (2012).

5 Chung, H. T. et al. Direct atomic-level insight into the active sites of a high-p erformance PGM-free ORR catalyst. Science 357, 479-484 (2017).

6 Ramaswamy, N., Tylus, U., Jia, Q. \& Mukerjee, S. Activity descriptor identific ation for oxygen reduction on nonprecious electrocatalysts: Linking surface scie nce to coordination chemistry. J. Am. Chem. Soc. 135, 15443-15449 (2013).

7 Kramm, U. I. et al. On an easy way to prepare metal-nitrogen doped carbon with exclusive presence of $\mathrm{MeN}_{4}$-type sites active for the ORR. J. Am. Chem. Soc. 138, 635-640 (2016).

8 Zitolo, A. et al. Identification of catalytic sites for oxygen reduction in iron- a nd nitrogen-doped graphene materials. Nat. Mater. 14, 937-942 (2015).

9 Fei, H. et al. Atomic cobalt on nitrogen-doped graphene for hydrogen generati on. Nat. Commun. 6, 8668 (2015).

10 Gong, K., Du, F., Xia, Z., Durstock, M. \& Dai, L. Nitrogen-doped carbon nan 
otube arrays with high electrocatalytic activity for oxygen reduction. Science 32 3, 760-764 (2009).

11 Guo, D. et al. Active sites of nitrogen-doped carbon materials for oxygen redu ction reaction clarified using model catalysts. Science 351, 361-365 (2016).

12 Ferrandon, M. et al. Stability of iron species in heat-treated polyaniline-iron-car bon polymer electrolyte fuel cell cathode catalysts. Electrochim. Acta 110, 282291 (2013).

13 Goellner, V. et al. Degradation of $\mathrm{Fe} / \mathrm{N} / \mathrm{C}$ catalysts upon high polarization in a cid medium. Phys. Chem. Chem. Phys. 16, 18454-18462 (2014).

14 Goellner, V., Armel, V., Zitolo, A., Fonda, E. \& Jaouen, F. Degradation by hy drogen peroxide of metal-nitrogen-carbon catalysts for oxygen reduction. J. Elec trochem. Soc. 162, H403-H414 (2015).

15 Choi, C. H. et al. Minimizing operando demetallation of Fe-N-C electrocatalyst s in acidic medium. ACS Catal. 6, 3136-3146 (2016).

16 Choi, C. H. et al. Stability of Fe-N-C catalysts in acidic medium studied by o perando spectroscopy. Angew. Chem. Int. Ed. 54, 12753-12757 (2015).

17 Lefèvre, M. \& Dodelet, J. P. Fe-based catalysts for the reduction of oxygen in polymer electrolyte membrane fuel cell conditions: Determination of the amou nt of peroxide released during electroreduction and its influence on the stability of the catalysts. Electrochim. Acta 48, 2749-2760 (2003).

$18 \mathrm{Wu}, \mathrm{G}$. et al. Performance durability of polyaniline-derived non-precious cathod e catalysts. ECS Trans. 25, 1299-1311 (2009).

19 Sahraie, N. R. et al. Quantifying the density and utilization of active sites in $\mathrm{n}$ on-precious metal oxygen electroreduction catalysts. Nat. Commun. 6, 8618 (20 
$15)$.

20 Brocato, S., Serov, A. \& Atanassov, P. pH dependence of catalytic activity for ORR of the non-PGM catalyst derived from heat-treated Fe-phenanthroline. Ele ctrochim. Acta 87, 361-365 (2013).

21 Nidheesh, P. V. Heterogeneous Fenton catalysts for the abatement of organic $p$ ollutants from aqueous solution: a review. RSC Adv. 5, $40552-40577$ (2015).

22 Yu, C., Wang, C. F. \& Chen, S. Facile access to graphene oxide from ferro-in duced oxidation. Sci. Rep. 6, 17071 (2016).

23 Guo, H. L., Wang, X. F., Qian, Q. Y., Wang, F. B. \& Xia, X. H. A green a pproach to the synthesis of graphene nanosheets. ACS Nano 3, 2653-2659 (200 9).

24 Zagal, J. H. \& Koper, M. T. M. Reactivity descriptors for the activity of mole cular $\mathrm{MN}_{4}$ catalysts for the oxygen reduction reaction. Angew. Chem. Int. Ed. 55, 14510-14521 (2016).

25 Choi, C. H. et al. Tuning selectivity of electrochemical reactions by atomically dispersed platinum catalyst. Nat. Commun. 7, 10922 (2016).

26 Kattel, S. \& Wang, G. Reaction pathway for oxygen reduction on $\mathrm{FeN}_{4}$ embed ded graphene. J. Phys. Chem. Lett. 5, 452-456 (2014).

27 Choi, C. H. et al. Long-range electron transfer over graphene-based catalyst for high-performing oxygen reduction reactions: Importance of size, N-doping, and metallic impurities. J. Am. Chem. Soc. 136, 9070-9077 (2014).

28 Cheon, J. Y. et al. Intrinsic relationship between enhanced oxygen reduction re action activity and nanoscale work function of doped carbons. J. Am. Chem. S oc. 136, 8875-8878 (2014). 
29 Trasatti, S. Work function, electronegativity, and electrochemical behaviour of metals: III. Electrolytic hydrogen evolution in acid solutions. J. Electroanal. Ch em. Interfacial Electrochem. 39, 163-184 (1972).

30 Varnell, J. A. et al. Identification of carbon-encapsulated iron nanoparticles as active species in non-precious metal oxygen reduction catalysts. Nat. Commun. 7, 12582 (2016). 


\section{Figures}
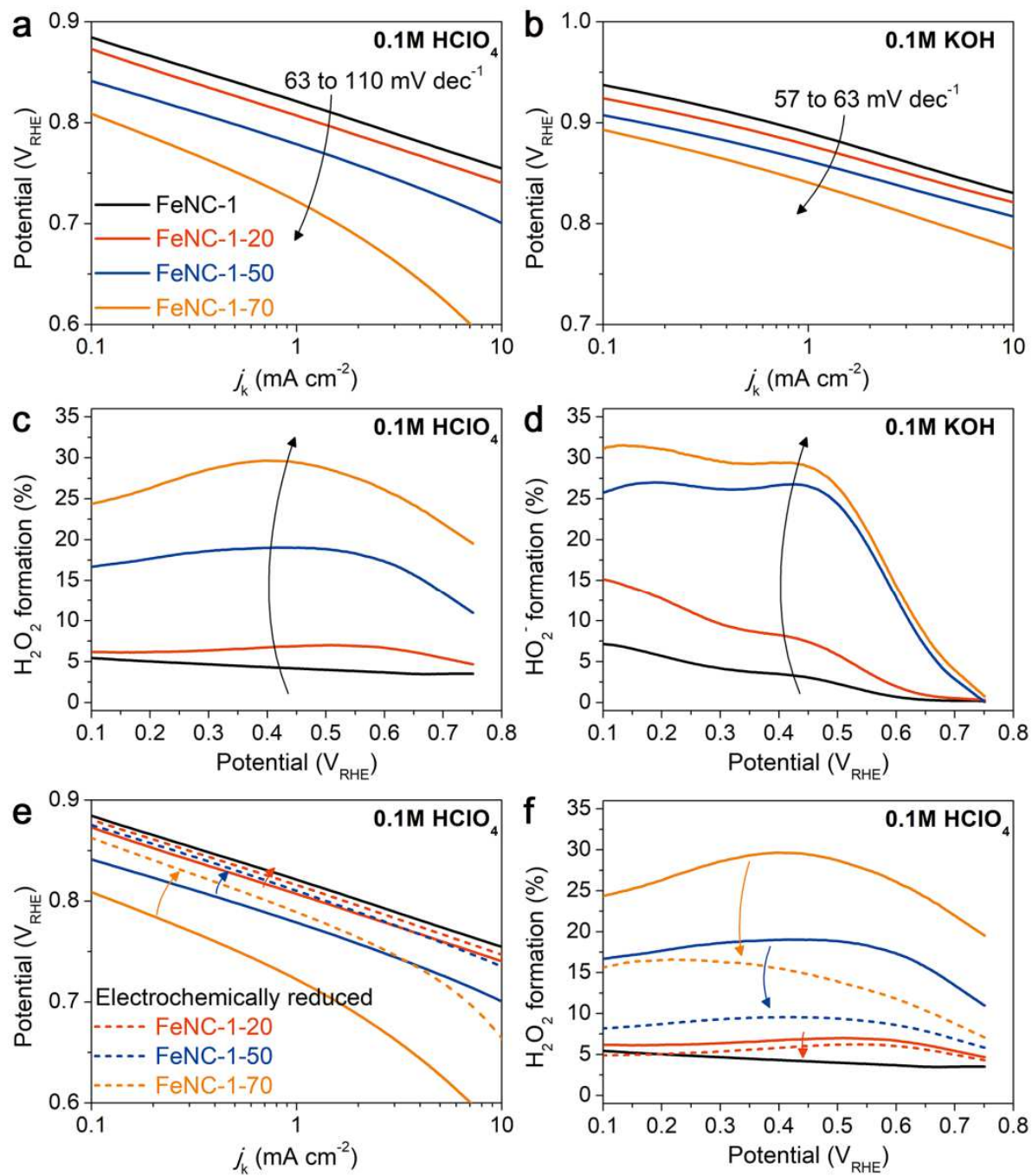

Figure 1 | Effects of acidic $\mathrm{H}_{2} \mathrm{O}_{2}$-treatment and subsequent electro-reduction in $0.5 \mathrm{M}$

$\mathrm{NaCl}$ on the ORR activity and selectivity of FeNC-1. a, b, ORR polarization curves after 2 hour treatment at $\mathrm{OCP}\left(c a .0 .84 \mathrm{~V}_{\mathrm{RHE}}\right)$ in $5 \mathrm{wt} \% \mathrm{H}_{2} \mathrm{O}_{2}$ in $0.1 \mathrm{M} \mathrm{HClO}_{4}, \mathbf{c}$, d, Peroxide formation during ORR after $\mathrm{H}_{2} \mathrm{O}_{2}$-treatment, e, ORR polarization curves after $\mathrm{H}_{2} \mathrm{O}_{2}$-treatment and electro-reduction in $0.5 \mathrm{M} \mathrm{NaCl}$, f, Peroxide formation during $\mathrm{ORR}$ after $\mathrm{H}_{2} \mathrm{O}_{2}$-treatment and electro-reduction in $0.5 \mathrm{M} \mathrm{NaCl}$. The electrolyte was $\mathrm{O}_{2}$-saturated $0.1 \mathrm{M} \mathrm{HClO}_{4}(\mathbf{a}, \mathbf{c}, \mathbf{e}, \mathbf{f})$ or $0.1 \mathrm{M} \mathrm{KOH}(\mathbf{b}, \mathbf{d})$. The two-digit number following FeNC-1 indicates the $\mathrm{H}_{2} \mathrm{O}_{2}$-treatment temperature. 

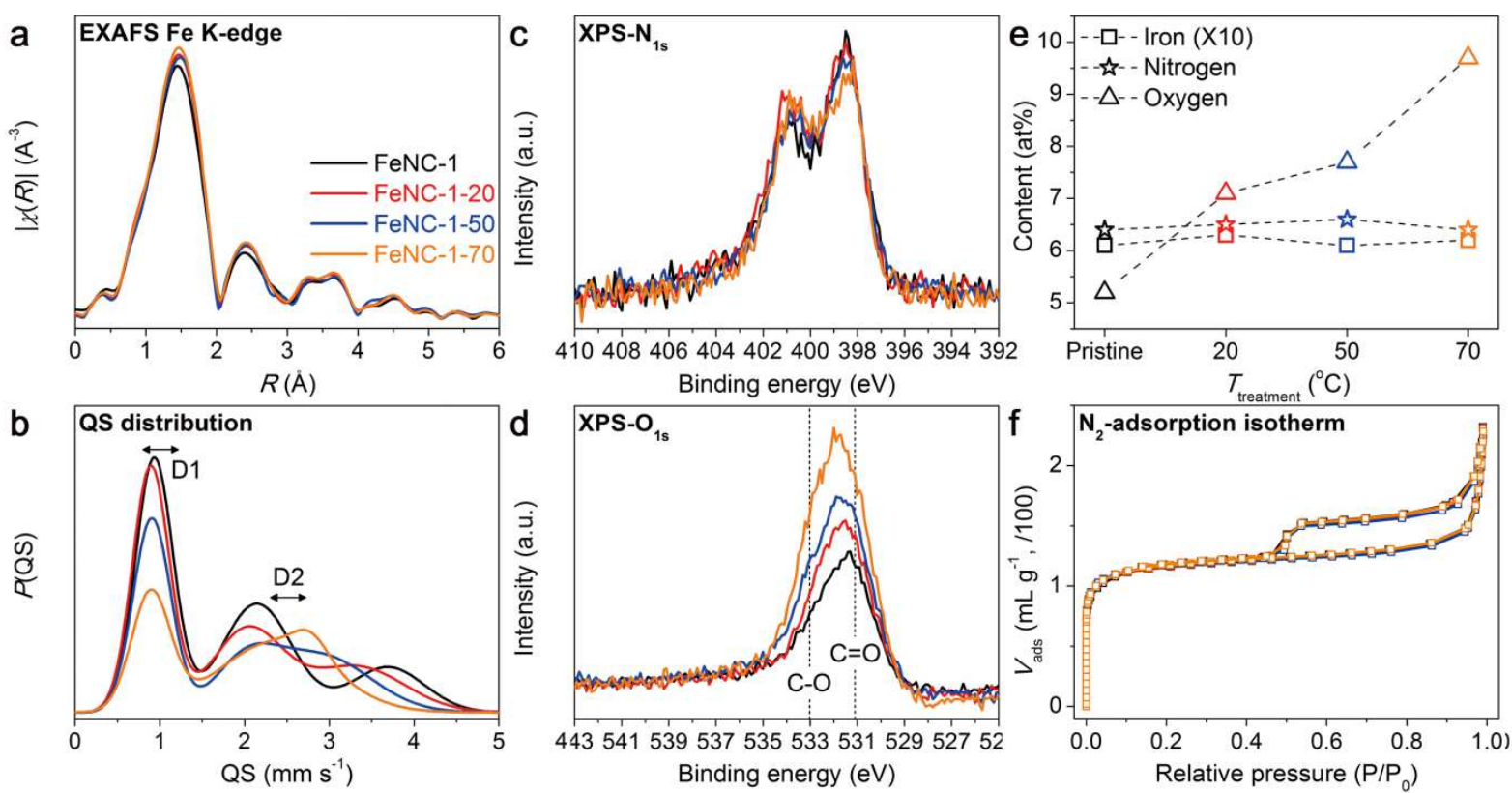

Figure 2 | Effects of acidic $\mathrm{H}_{2} \mathrm{O}_{2}$-treatment on Fe coordination, contents of iron, nitrogen, oxygen and porous structure of FeNC-1. a, $k^{2}$-weighted Fourier transforms of the Fe K-edge EXAFS spectra. b, ${ }^{57} \mathrm{Fe}$ Mössbauer quadrupole splitting distributions. c, XPS-N $\mathrm{N}_{1 \mathrm{~s}}$ spectra. d, $\mathrm{XPS}_{-} \mathrm{O}_{1 \mathrm{~s}}$ spectra. e, $\mathrm{N}$ and $\mathrm{O}$ contents measured by XPS and Fe-contents measured by ICPAES. f, $\mathrm{N}_{2}$-adsorption isotherms (BET specific area and pore volume for all samples are $435 \pm$ $5 \mathrm{~m}^{2} \mathrm{~g}^{-1}$ and $0.35 \pm 0.01 \mathrm{~cm}^{3} \mathrm{~g}^{-1}$, respectively). FeNC-1 was treated for 2 hours at OCP (ca. $\left.0.84 \mathrm{~V}_{\mathrm{RHE}}\right)$ in $5 \mathrm{wt} \% \mathrm{H}_{2} \mathrm{O}_{2}$ in $0.1 \mathrm{M} \mathrm{HClO}_{4}$ at 20,50 or $70{ }^{\circ} \mathrm{C}$. EXAFS, ${ }^{57} \mathrm{Fe}$ Mössbauer spectroscopy and ICP-AES are bulk techniques while XPS, probing several $\mathrm{nm}$ below the surface, is not a true surface-specific technique when applied to carbon materials. Note 1: $\mathrm{Fe}_{2 \mathrm{p}}$ signal measured with XPS was too noisy for Fe quantification. Note 2: All data were measured on FeNC-1 series, except for Mössbauer spectra (see Fig. S6). Note 3: The relative carbon content decrease that can be deduced from Fig. 2e results from the addition of oxygen groups on the surface, not from the irreversible loss of carbon atoms. 


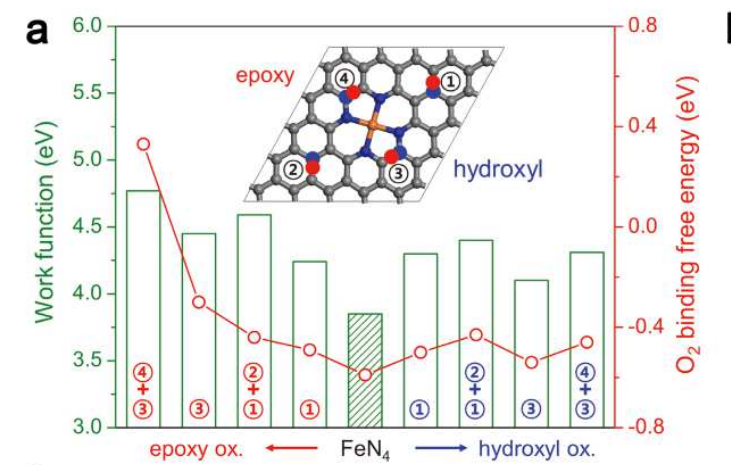

b
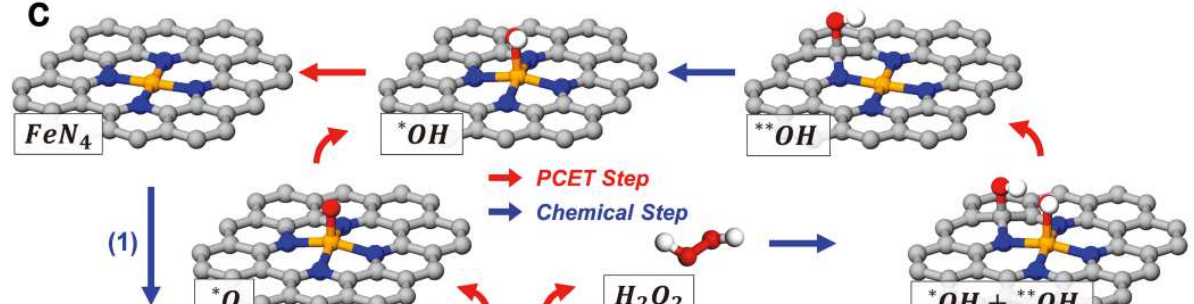

(1)

(3) $\Gamma_{(5)} \mathrm{H}_{2} \mathrm{O}_{2}$

${ }^{*} \mathrm{OH}+{ }^{* *} \mathrm{OH}$
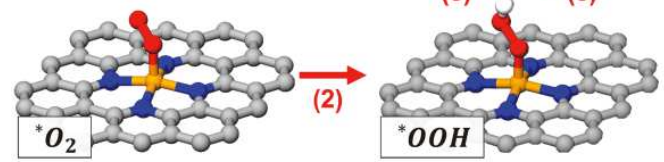

$(4)$

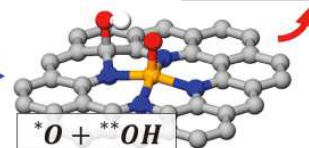

Figure 3 | First-principle DFT analysis of the effect of surface oxidation on a FeN 4 moiety

embedded in a basal graphene plane. a, $\mathrm{O}_{2}$-binding energy of $\mathrm{FeN}_{4}$ and electron work function. The surface is either oxygen-free or oxidized with one or two oxygen-functionalities, at positions as indicated in the insets. b, Scheme of electron depletion at the $\mathrm{FeN}_{4}$ center induced by surface oxidation. c, ORR pathways at $\mathrm{FeN}_{4}$. Single and double asterisks denote reaction intermediates adsorbed on the Fe-center and nearest $\mathrm{C}$-center, respectively. 

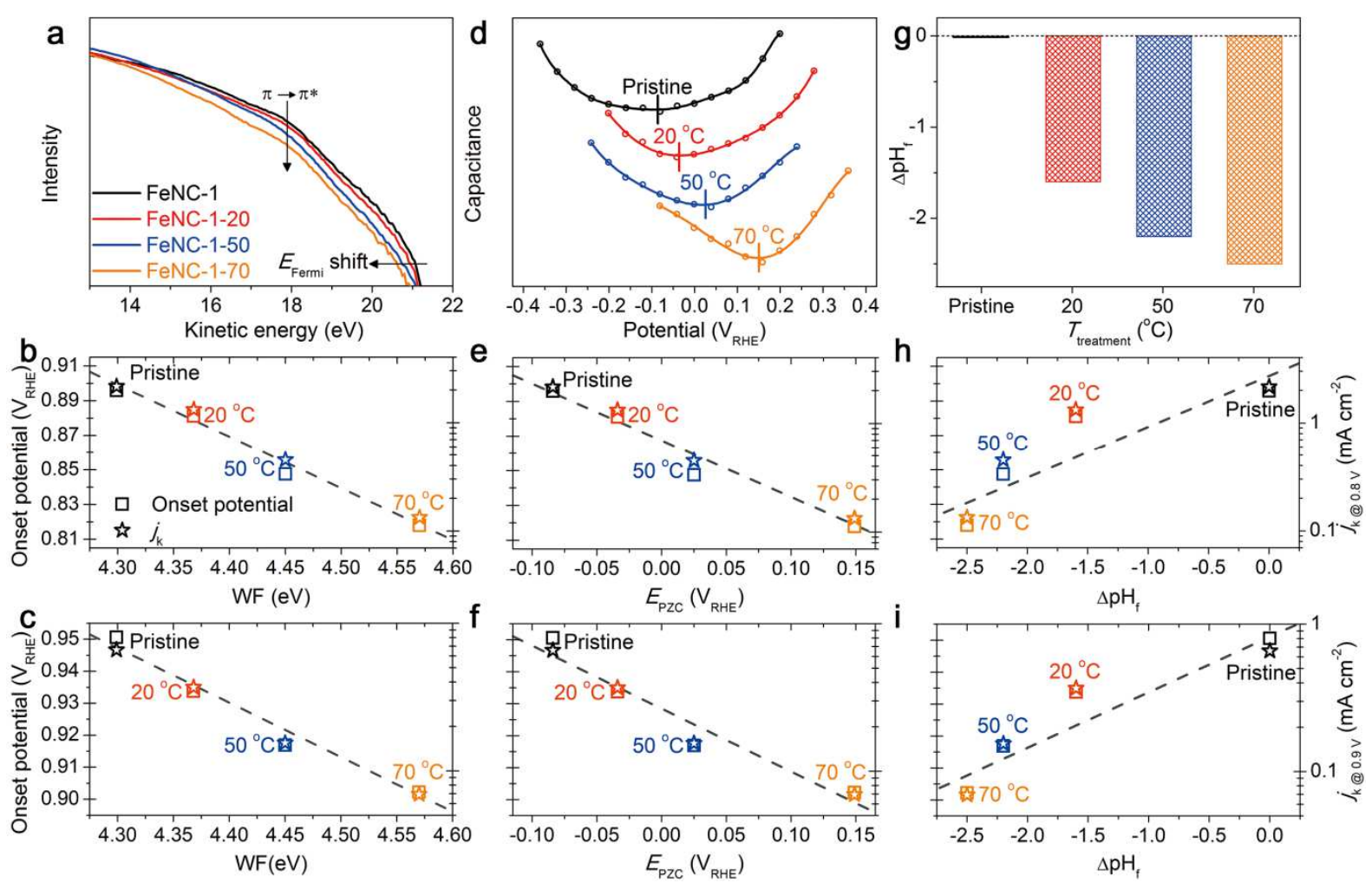

Figure 4 | Effects of acidic $\mathrm{H}_{2} \mathrm{O}_{2}$-treatment on surface properties and correlations between $\mathrm{ORR}$ activity and surface properties. a-c, WF, $\mathbf{d - f}, E_{\mathrm{PZC}}$ and $\mathbf{g - i}$, surface basicity variation $\left(\Delta \mathrm{pH}_{\mathrm{f}}\right)$. Correlations between the ORR activity in $0.1 \mathrm{M} \mathrm{HClO}_{4}$ and $\mathrm{WF}(\mathbf{b}), E_{\mathrm{PZC}}(\mathbf{e})$ or $\Delta \mathrm{pH}_{\mathrm{f}}(\mathbf{h})$. Correlations between the ORR activity in $0.1 \mathrm{M} \mathrm{KOH}$ and $\mathrm{WF}(\mathbf{c}), E_{\mathrm{PZC}}(\mathbf{f})$ or $\Delta \mathrm{pH}_{\mathrm{f}}(\mathbf{i})$. The activity was quantified either by onset potential (left-handside axis, open square symbol) or by the kinetic current density $j_{\mathrm{k}}$ (right-handside axis, open star symbol, reported for 0.8 and $0.9 \mathrm{~V}_{\mathrm{RHE}}$ in $\mathrm{HClO}_{4}$ and $\mathrm{KOH}$ electrolytes, respectively). A logarithmic scale was used for $j_{\mathrm{k}}$ since it is logarithmically related the onset potential via the Tafel law. 
Supporting Information

\section{Achilles' heel of iron-based catalysts during oxygen reduction in}

\section{acidic medium}

Chang Hyuck Choi ${ }^{1 *}$, Hyung-Kyu Lim $^{2}$, Gajeon Chon ${ }^{1}$, Min Wook Chung ${ }^{1}$, Abdulrahman Altin $^{3}$, Nastaran Ranjbar Sahraie ${ }^{4}$, Moulay-Tahar Sougrati ${ }^{4}$, Lorenzo Stievano ${ }^{4}$, Hyun Seok $\mathrm{Oh}^{5}$, Eun Soo Park ${ }^{5}$, Fang Luo ${ }^{6}$, Peter Strasser ${ }^{6}$, Goran Dražić ${ }^{7}$, Karl J. J. Mayrhofer ${ }^{3,8,9}$, Hyungjun $\mathrm{Kim}^{2 *} \&$ Frédéric Jaouen ${ }^{4 *}$

${ }^{1}$ School of Materials Science and Engineering, Gwangju Institute of Science and Technology, 61005 Gwangju, Republic of Korea.

${ }^{2}$ Department of Chemistry, Graduate School of EEWS, Korea Advanced Institute of Science and Technology, 34141 Daejeon, Republic of Korea.

${ }^{3}$ Department of Interface Chemistry and Surface Engineering, Max-Planck Institut für Eisenforschung GmbH, Max-Planck-Str. 1, 40237 Düsseldorf, Germany.

${ }^{4}$ Institut Charles Gerhardt Montpellier, UMR CNRS 5253, Agrégats, Interfaces et Matériaux pour l'Energie, Université de Montpellier, 34095 Montpellier Cedex 5, France.

${ }^{5}$ Department of Materials Science and Engineering, Seoul National University, 08826 Seoul, Republic of Korea.

${ }^{6}$ Department of Chemistry, Chemical Engineering Division, Technical University Berlin, 10623 Berlin, Germany.

${ }^{7}$ Department of Materials Chemistry, National Institute of Chemistry, Hajdrihova 19, 1001 Ljubljana, Slovenia.

${ }^{8}$ Helmholtz-Institute Erlangen-Nürnberg for Renewable Energy (IEK-11), Forschungszentrum 
Jülich, Egerlandstr. 3, 91058 Erlangen, Germany.

${ }^{9}$ Department of Chemical and Biological Engineering, Friedrich-Alexander-Universität Erlangen-Nürnberg, Egerlandstr. 3, 91058 Erlangen, Germany.

*Correspondence to: Chang Hyuck Choi (chchoi@gist.ac.kr), Hyungjun Kim (linus16@kaist.ac.kr) or Frédéric Jaouen (frederic.jaouen@umontpellier.fr) 


\section{Experimental Section}

Catalyst synthesis and $\mathrm{H}_{2} \mathrm{O}_{2}$-treatment. FeNC-1 and FeNC-0.5 were prepared from $\mathrm{Fe}^{\mathrm{II}}$ acetate, 1,10-phenanthroline (phen), and a $\mathrm{Zn}^{\mathrm{II}}$ zeolitic imidazolate framework (ZIF-8 with formula $\mathrm{ZnN}_{4} \mathrm{C}_{8} \mathrm{H}_{12}$, purchased from BASF under trademark Basolite $\mathrm{Z} 1200$ ). One gram of a catalyst precursor containing 1.0 or $0.5 \mathrm{wt} \%$ Fe with a mass-ratio phen/ZIF-8 of 20/80 was prepared by dry ball-milling. The milling was carried out in a $\mathrm{ZrO}_{2}$ crucible with $100 \mathrm{ZrO}_{2}$ balls of $5 \mathrm{~mm}$ diameter using a planetary ball-miller (FRITSCH Pulverisette 7 Premium) for 4 cycles of $30 \mathrm{~min}$ at $400 \mathrm{rpm}$. The resulting catalyst precursors were then pyrolyzed at $1050{ }^{\circ} \mathrm{C}$ in $\mathrm{Ar}$ for $1 \mathrm{~h}$, leading to FeNC-1 and FeNC-0.5. The $\mathrm{H}_{2} \mathrm{O}_{2}$-treatment was performed in a $0.1 \mathrm{M}$ $\mathrm{HClO}_{4}$ or $0.1 \mathrm{M} \mathrm{KOH}$ solution containing $5 \mathrm{wt} \% \mathrm{H}_{2} \mathrm{O}_{2}$, referred to as the oxidizing solution. It was prepared from concentrated $\mathrm{HClO}_{4}\left(70 \%\right.$, Aldrich), $\mathrm{H}_{2} \mathrm{O}_{2}(30 \mathrm{wt} \%$, Aldrich) and ultrapure water (18 $\mathrm{M} \Omega$, Millipore). For physical characterization purposes, the $\mathrm{H}_{2} \mathrm{O}_{2}$-treatment was performed with $0.05 \mathrm{~g}$ of Fe-N-C catalyst dispersed into $300 \mathrm{~mL}$ of the oxidizing solution at 20,50 or $70{ }^{\circ} \mathrm{C}$. After $2 \mathrm{~h}$, the catalyst powder was collected by filtration, washed with $1 \mathrm{~L}$ ultrapure water and dried at $80{ }^{\circ} \mathrm{C}$. For electrochemical characterization purposes, the FeNC-1 based catalytic layer (loading $800 \mu \mathrm{g} \mathrm{cm}^{-2}$ ) deposited on the glassy carbon tip ( $3 \mathrm{~mm}$ diameter) was immersed in $100 \mathrm{~mL}$ of the oxidizing solution for $2 \mathrm{~h}$, a method similar to that previously employed ${ }^{1}$, with the electrode rotated at $2000 \mathrm{rpm}$ to remove $\mathrm{O}_{2}$-bubbles formed from $\mathrm{H}_{2} \mathrm{O}_{2}$ disproportionation and the electrode potential was either set at $0.5 \mathrm{~V}_{\mathrm{RHE}}$ or left at open-circuit potential (OCP). The OCP value of FeNC-1 was $c a .0 .84 \mathrm{~V}_{\mathrm{RHE}}$ in $0.1 \mathrm{M} \mathrm{HClO}_{4}$ and $c a .0 .94$ $\mathrm{V}_{\mathrm{RHE}}$ in $0.1 \mathrm{M} \mathrm{KOH}$.

Physico-chemical characterizations. Inductively coupled plasma-atomic emission spectrometry analysis (ICP-AES) was carried out using a POLYSCAN 61E (Hewlett-Packard). 
Electron paramagnetic resonance (EPR) was performed using a Bruker EMX/Plus spectrometer equipped with a dual mode cavity (ER 4116DM). The experimental conditions are as follows: $9.64 \mathrm{GHz}$ microwave frequency, $10 \mathrm{G}$ modulation amplitude, $100 \mathrm{kHz}$ modulation frequency, $0.94 \mathrm{~mW}$ microwave power and $298 \mathrm{~K}$ temperature. For each spectrum 10 scans were accumulated. EPR aliquot samples were prepared as follows. A mass of $1.8 \mathrm{mg}$ FeNC- 0.5 catalyst was dispersed in either $0.1 \mathrm{M} \mathrm{HClO}_{4}$ or $0.1 \mathrm{M} \mathrm{KOH}$ solution. After 30 min of sonication, the desired amounts of 5,5-Dimethyl-1-pyrroline N-oxide (DMPO; >98\%, Aldrich) and hydrogen peroxide were sequentially added to reach the concentrations of $0.4 \mathrm{M}$ and $0.5 \mathrm{wt} \%$, respectively. The resulting total volume of the solution was $0.5 \mathrm{~mL}$. After $5 \mathrm{~min}$ of reaction, the solution was filtered (syringe polypropylene filter, $0.2 \mu \mathrm{m}$, Whatman) to separate the catalyst powder from the liquid aliquot that was subsequently examined with EPR.

X-ray absorption spectroscopy (XAS) at the Fe K-edge was measured in transmission mode at Pohang Accelerator Laboratory (7D-XAFS beamline). A mass of $0.1 \mathrm{~g}$ catalyst was mounted in a sample holder $\left(w \times l \times d=3 \times 8 \times 2 \mathrm{~mm}^{3}\right)$. The XAS energy scale was calibrated using a Fe foil before and after the measurement to verify the lack of or correct for any energy shift during data acquisition. For extended X-ray absorption fine structure (EXAFS) analysis, Artemis implemented in Demeter program package (0.9.23) was utilized after the data processing in Athena $^{2}$. EXAFS amplitudes and phase shifts were calculated by FEFF7. The many body attenuation factor $\left(S_{0}^{2}\right)$ was determined as 0.82 from the fit of the EXAFS of reference materials. Interatomic distances $(\mathrm{R})$ and the Debye-Waller factors were calculated for all paths included in the fits. ${ }^{57} \mathrm{Fe}$ Mössbauer spectra were measured with a source of ${ }^{57} \mathrm{Co}-\mathrm{Rh}$. The measurements were performed with both the source and the absorber at room temperature. The 
spectrometer was operated with a triangular velocity waveform, and a NaI scintillation detector was used for detecting the $\gamma$-rays. Velocity calibration was performed with an $\alpha$-Fe foil, to which all isomer shifts are referred. The broadened quadrupole components of the Mössbauer spectra were analysed in Fig. S6 by assuming Gaussian distributions of the electric quadrupole interaction. Three independent Gaussian distribution components were necessary to fit coherently the whole series of collected spectra. $\mathrm{CO}$ pulse chemisorption was performed with a Thermoscientific TPD/R/O 1110 instrument under $20 \mathrm{~mL} \mathrm{~min}^{-1} \mathrm{He}$ flow. Typically, 100-150 mg catalyst was cleaned by heating at $20{ }^{\circ} \mathrm{C} \min ^{-1}$ to $600{ }^{\circ} \mathrm{C}$ (hold time $15 \mathrm{~min}$ ) in $\mathrm{He}$, and then cooled down to room temperature. CO pulse chemisorption was then carried out at $193 \mathrm{~K}$ with the sample holder immersed in a dry ice and acetone mix. Six CO pulses $(0.338 \mathrm{~mL})$ were carried out at 25 min interval. The adsorbed $\mathrm{CO}$ amount was quantified from the difference between the area below peaks No. 4-6 and that below peaks No. 1-3. From the adsorbed CO amount and the bulk Fe content measured by ICP, the relative amount of Fe that is on the surface and interacts with $\mathrm{CO}$ was calculated, assuming one $\mathrm{CO}$ molecule binds per $\mathrm{FeN}_{\mathrm{x}} \mathrm{C}_{\mathrm{y}}$ moiety. The relative amount of surface Fe probed by $\mathrm{CO}$ chemisorption may underestimate the true amount of surface Fe, if some surface $\mathrm{FeN}_{\mathrm{x}} \mathrm{C}_{\mathrm{y}}$ moieties do not bind $\mathrm{CO} . \mathrm{N}_{2}$ adsorptiondesorption isotherms were measured using a BEL-sorp-max (BEL Japan) volumetric analyzer at $77 \mathrm{~K}$. Before each measurement, the sample was degassed at $200{ }^{\circ} \mathrm{C}$ for $4 \mathrm{~h}$. The specific areas were determined in the $\mathrm{P} / \mathrm{P}_{0}$ range of $0.05-0.15$ using the Brunauer-Emmett-Teller (BET) equation.

Probe Cs-corrected scanning transmission electron microscope Jeol ARM 200 F, equipped with a cold field emission electron source, was used for imaging atomically-dispersed $\mathrm{FeN}_{\mathrm{x}} \mathrm{C}_{\mathrm{y}}$ moieties, and possibly binuclear $\mathrm{Fe}_{2} \mathrm{~N}_{\mathrm{x}} \mathrm{C}_{\mathrm{y}}$ moieties, in FeNC-1. To minimize the beam damage, 
$80 \mathrm{keV}$ and low beam current were used. High-angle annular dark-field (HAADF) images were obtained using 68-180 mrad collection half-angles at 24 mrad probe convergence semi-angle. Images were filtered with non-linear filter which is a combination of low-pass and Wiener filters $^{3}$. The presence of iron and nitrogen was confirmed with Gatan Quantum ER dual Electron Energy-loss Spectroscopy (EELS) system.

X-ray photoelectron spectroscopy (XPS) and ultraviolet photoelectron spectroscopy (UPS) data acquisition were carried out using a Sigma Probe (Thermo VG Scientific) equipped with a microfocused monochromator X-ray source. The XPS data were analysed using the XPSPEAK41 software with $\pm 0.1 \mathrm{eV}$ deviation in binding energy. The binding energies used for deconvoluting the XPS- $\mathrm{N}_{1 \mathrm{~s}}$ spectra were $398.5 \mathrm{eV}$ for pyridinic- $\mathrm{N}, 400.1 \mathrm{eV}$ for pyrrolic$\mathrm{N}, 401.1 \mathrm{eV}$ for graphitic-N and $403.7 \mathrm{eV}$ for pyridinic-oxide, respectively ${ }^{4}$. The binding energies used for deconvoluting the $\mathrm{XPS}-\mathrm{O}_{1 \mathrm{~s}}$ spectra were $531.2 \mathrm{eV}$ for $\mathrm{C}=\mathrm{O}$ and $533.0 \mathrm{eV}$ for C-O, respectively ${ }^{5,6}$. UPS data were analysed with He I radiation. The work function (WF) values were derived from the following equation

$\mathrm{WF}=h v-\left|E_{\mathrm{sec}}-E_{\text {Fermi }}\right|$

where $h v$ is the $21.2 \mathrm{eV}$ radiation energy of He I source, $E_{\mathrm{sec}}$ is the onset of the secondary emission, and $E_{\mathrm{Fermi}}$ is the Fermi edge level. The potential of zero charge, $E_{\mathrm{PZC}}$, was measured using a VPM3 potentiostat (BioLogic) installed with a function of staircase potentiostatic electrochemical impedance spectroscopy. The measurements were performed in a $2 \mathrm{mM} \mathrm{NaF}$ electrolyte from -1.5 to $0.5 \mathrm{~V}_{\mathrm{Ag} / \mathrm{AgCl}}$ at $100 \mathrm{mHz}$ frequency and with a $10 \mathrm{mV}$ potential amplitude. E EZC was determined as the potential at which the electrochemical double layer shows a minimum capacitance. Basicity of the catalytic surface was measured by dispersing $40 \mathrm{mg}$ of FeNC-1 or $\mathrm{H}_{2} \mathrm{O}_{2}$-treated FeNC-1 catalysts in $20 \mathrm{~mL}$ of an aqueous solution of initial 
$\mathrm{pH}\left(\mathrm{pH}_{\mathrm{i}}\right) 6$ prepared from $0.1 \mathrm{M} \mathrm{H}_{2} \mathrm{SO}_{4}$ and $0.1 \mathrm{M} \mathrm{KOH}$ solutions, continuously saturated with bubbling $\mathrm{N}_{2}$ to prevent acidification from airborne $\mathrm{CO}_{2}{ }^{7}$. The final $\mathrm{pH}$ after equilibration was recorded once the $\mathrm{pH}$-meter indicated a stable value. For Fe-N-C catalysts, we previously reported that the entire curve $\mathrm{pH}_{\mathrm{f}}=\mathrm{f}\left(\mathrm{pH}_{\mathrm{i}}\right)$, with $\mathrm{pH}_{\mathrm{i}}$ values ranging from 1 to 13 , shows a plateau of $\mathrm{pH}_{\mathrm{f}}$ values, at near-neutral $\mathrm{pH}_{\mathrm{i}}$ values, and discussed that the plateau of $\mathrm{pH}_{\mathrm{f}}$ is a measure of the surface basicity ${ }^{7,8}$. For comparing the basicity of $\mathrm{H}_{2} \mathrm{O}_{2}$-treated samples relative to pristine FeNC-1, we therefore used the $\mathrm{pH}$ variation $\Delta \mathrm{pH}_{\mathrm{f}}=\mathrm{pH}_{\mathrm{f}}\left(\mathrm{H}_{2} \mathrm{O}_{2}\right.$-treated FeNC-1)$\mathrm{pH}_{\mathrm{f}}$ (pristine FeNC-1).

Electrochemical characterizations. The electrochemical properties were studied with a modulated speed rotator (RRDE-3A, ALS) in a three-electrode Teflon cell equipped with a graphite rod as a counter electrode and a saturated $\mathrm{Ag} / \mathrm{AgCl}$ as a reference electrode (RE-1A for acidic medium and RE-16 for alkaline medium, EC-Frontier). $0.1 \mathrm{M} \mathrm{HClO}_{4}$ and $0.1 \mathrm{M}$ $\mathrm{KOH}$ solutions were used as acidic and alkaline electrolytes, respectively. They were prepared from concentrated $\mathrm{HClO}_{4}(70 \%$, Aldrich) and $\mathrm{KOH}$ pellet (90\%, Aldrich) with ultrapure water (18 $\mathrm{M} \Omega$, Millipore). Before any electrochemical measurements, the $\mathrm{Ag} / \mathrm{AgCl}$ reference electrodes were calibrated against a Pt electrode in $\mathrm{H}_{2}$-saturated electrolyte to correctly convert potentials to the reversible hydrogen electrode (RHE) scale. ORR activity was investigated at a loading of $800 \mu \mathrm{g}_{\mathrm{FeNC}} \mathrm{cm}^{-2}$ (ca. $25 \mu \mathrm{g}_{\mathrm{Fe}} \mathrm{cm}^{-2}$ for FeNC-1). The catalyst ink was prepared by dispersing $10 \mathrm{mg}$ catalyst in $884 \mu \mathrm{L}$ aliquot $(804 \mu \mathrm{L}$ water and $80 \mu \mathrm{L}$ of $5 \mathrm{wt} \%$ Nafion solution). The working electrode was prepared by pipetting $5 \mu \mathrm{L}$ of catalyst ink onto the glassy carbon disk $\left(0.071 \mathrm{~cm}^{2}\right)$ of the rotating disk electrode $(011169$, ALS $)$, which was then left to dry at room temperature. For comparison, a 46 wt\% Pt/C (TEC10E50E, Tanaka) electrode was prepared with $20 \mu \mathrm{g}_{\mathrm{Pt}} \mathrm{cm}^{-2} \mathrm{Pt}$ loading. The ORR polarization curves were recorded with a scan 
rate of $10 \mathrm{mV} \mathrm{s}^{-1}$ and a rotation speed of $900 \mathrm{rpm}$ in an $\mathrm{O}_{2}$-saturated electrolyte. ORR Faradaic currents were obtained after subtraction of the polarization curves measured identically but in Ar-saturated electrolyte. Onset potential was defined as the potential at which $0.1 \mathrm{~mA} \mathrm{~cm}{ }^{-2}$ current density is reached.

Rotating ring disk electrode (RRDE) analysis was carried out using a RRDE electrode (012613, ALS) composed with Pt ring and glassy carbon disk electrodes. During the measurement, the Pt ring disk was set at $1.2 \mathrm{~V}_{\mathrm{RHE}}$ and the electrode was rotated at $900 \mathrm{rpm} . \mathrm{H}_{2} \mathrm{O}_{2}$ selectivity was calculated using the following equation

$\mathrm{H}_{2} \mathrm{O}_{2}(\%)=200 \times I_{\mathrm{R}} / N /\left(I_{\mathrm{D}}+I_{\mathrm{R}} / N\right)$

where $I_{\mathrm{R}}$ is the ring current, $I_{\mathrm{D}}$ is the disk current and $N$ is the collection efficiency $(0.32$, as determined by $\mathrm{Fe}^{2+/ 3+}$ redox calibration).

All electrochemical experiments on the ORR activity and selectivity on FeNC-1, peroxidetreated FeNC-1 and electrochemically-reduced peroxide-treated FeNC-1 were carried out at least two times for reproducibility assessment. The reproducibility error was $c a . \pm 10 \%$ on the ORR activity (relative to the average activity at $0.8 \mathrm{~V}_{\mathrm{RHE}}$, acid, or $0.9 \mathrm{~V}_{\mathrm{RHE}}$, alkaline) and $c a$. $\pm 2 \%$ on the selectivity (absolute variation of $\%$ peroxide detected during RRDE at $0.5 \mathrm{~V}_{\mathrm{RHE}}$ ).

Electrochemical reduction of $\mathrm{H}_{2} \mathrm{O}_{2}$-treated $\mathrm{FeNC}-1$ and $\mathrm{FeNC}-0.5$. Electrochemical reduction of the carbon surface on FeNC-1-20, -50 and -70 and FeNC-0.5-70 was carried out by cyclic voltammetry (CV) in an Ar-saturated $0.5 \mathrm{M} \mathrm{NaCl}$ electrolyte, a method similar to that employed for electrochemical reduction of graphene oxide to graphene ${ }^{9,10} .100$ cycles were progressed between 0 and $-1.6 \mathrm{~V}_{\mathrm{Ag} / \mathrm{AgCl}}$ with a scan rate of $100 \mathrm{mV} \mathrm{s}^{-1}$. The lower potential limit was selected to avoid significant hydrogen evolution at even lower potential, leading to active-layer detachment. 
Computational methods. We performed first-principle DFT calculations coupled with the Poisson-Boltzmann (PB) implicit solvation effect on models for active sites with different environments as shown in Fig. S7a. We used the Vienna Ab-initio Simulation Package $(\mathrm{VASP})^{11}$, with the exchange-correlation function of revised Perdew-Burke-Ernzerhof $(\mathrm{RPBE})^{12}$. The electron-ion interaction was considered in the form of the projector-augmentedwave (PAW) method with a plane wave up to energy of $600 \mathrm{eV}$. The active site models combined with a $20 \AA$ vacuum layer along the $\mathrm{z}$-axis were fully minimized under a gamma centered k-point grid of $(4 \times 4 \times 1)$. A dipole correction was applied to all calculation cases to avoid unwanted electrostatic interaction between periodic images along the z-direction. To calculate the solvation energy, the PB implicit solvation model, which is implemented in the VASP program ${ }^{13}$, was used under a dielectric constant $\varepsilon=80$ for water (we neglect the cavitation energy contribution). We also calculated the vibrational internal energy and entropy terms for adsorbate molecules by taking account partial Hessian analysis. The partial density of states (PDOS) data was calculated with the conditions of tetrahedron method with Blöchl corrections and manipulated with p4vasp software. 


\section{Supporting Figures and Table}
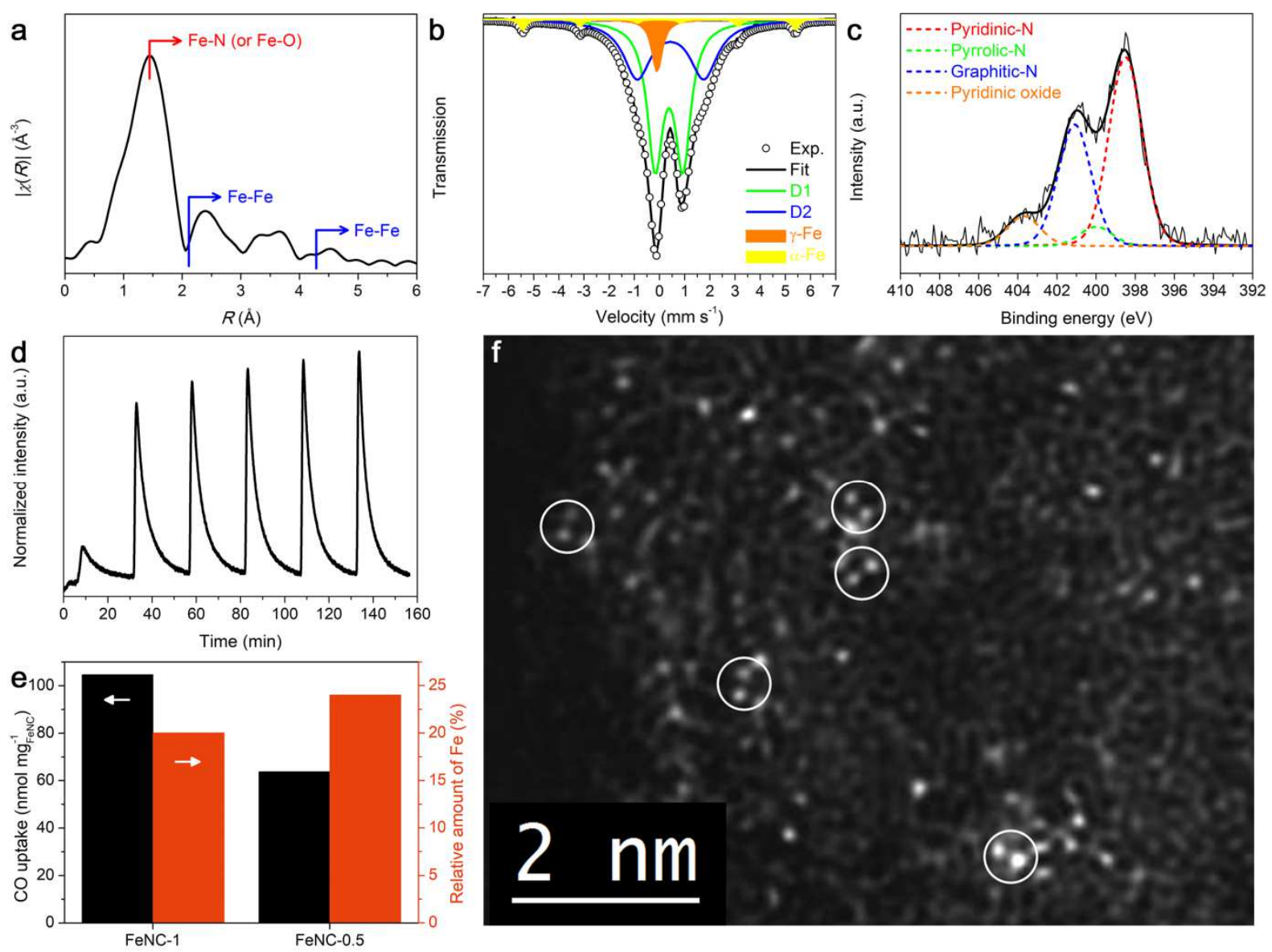

Figure S1 | Physico-chemical characterizations of FeNC-1. a, $k^{2}$-weighted Fourier transforms of Fe K-edge EXAFS on FeNC-1. The analysis showed a predominant presence of Fe-N (or Fe-O) coordination $\left(\mathrm{CN}_{\mathrm{Fe}-\mathrm{N}}=4\right.$ and $\mathrm{CN}_{\mathrm{Fe}-\mathrm{O}}=1$ ) and a minor presence of $\mathrm{Fe}-\mathrm{Fe}$ coordination $\left(\mathrm{CN}_{\mathrm{Fe}-\mathrm{Fe}}=0.6\right)$. b, Mössbauer spectrum of FeNC-1. D1 and D2 were assigned to $\mathrm{FeN}_{\mathrm{x}} \mathrm{C}_{\mathrm{y}}$ moieties with low and medium spins, respectively. $\mathrm{c}, \mathrm{XPS}-\mathrm{N}_{1 \mathrm{~s}}$ spectrum of FeNC-1. The signal was deconvoluted with pyridinic-N, pyrrolic-N, graphitic-N and pyridinic-oxide peaks. d, Carbon monoxide pulse-chemisorption profiles of FeNC-1, measured at $193 \mathrm{~K}$. e, Absolute $\mathrm{CO}$ uptake and relative Fe amount located on the surface for FeNC-1 and FeNC-0.5, comprising bulk Fe contents of 3.0 and $1.5 \mathrm{wt} \%$, respectively. f, Filtered HAADF-STEM image of FeNC-1 (scale bar $=1 \mathrm{~nm})$. The image shows the disordered nature of the carbon surface 
with many defects and non-hexagonal rings of light atoms, as well as atomically-dispersed iron atoms. Pairs of iron atoms are visible with Fe-Fe distances of $2.5 \pm 0.1 \AA$ (white circles), commensurate with the expected $\mathrm{Fe}-\mathrm{Fe}$ distance in binuclear $\mathrm{Fe}_{2} \mathrm{~N}_{5} \mathrm{C}_{\mathrm{y}}$ sites ${ }^{14,15}$. The present top-view image can however not confirm if Fe atoms of such apparent pairs are in a same or in different graphene sheets. 

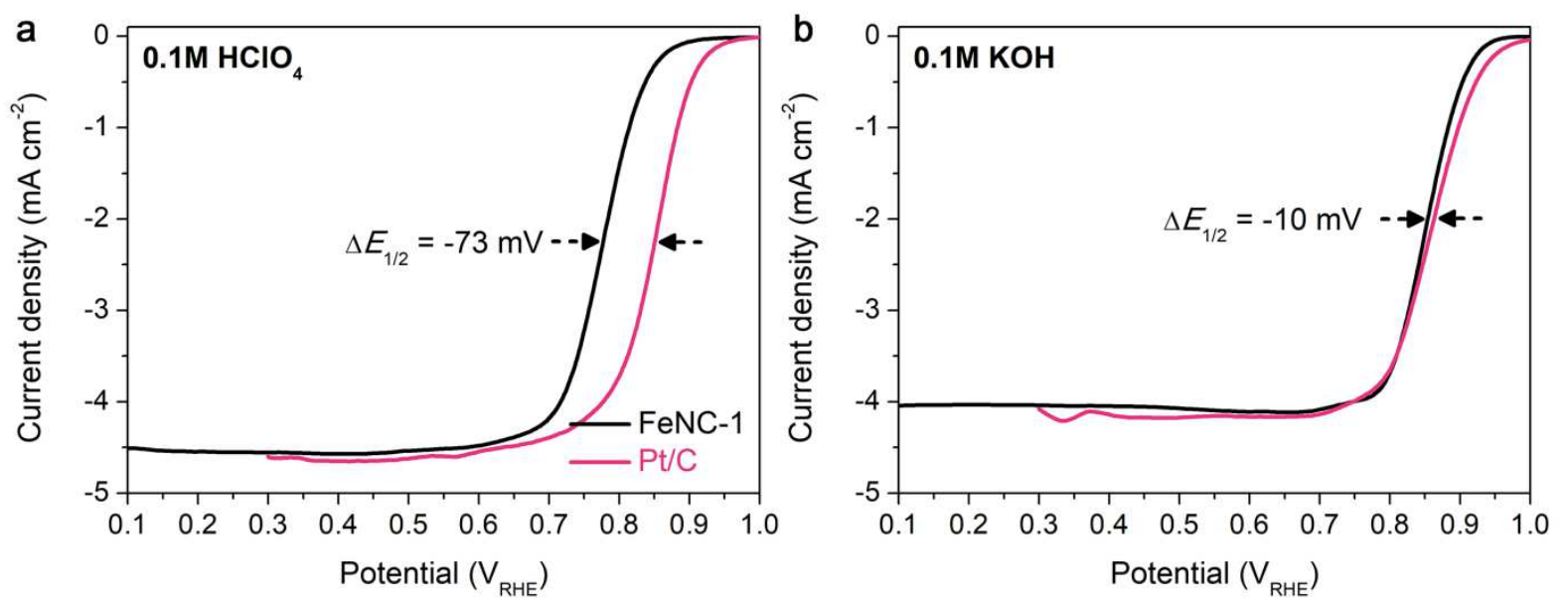

Figure S2 | ORR activity of pristine FeNC-1 catalyst. a, b, ORR polarization curves of FeNC-1 measured at $900 \mathrm{rpm}$ in $\mathrm{O}_{2}$-saturated $0.1 \mathrm{M} \mathrm{HClO}_{4}(\mathbf{a})$ and $\mathrm{O}_{2}$-saturated $0.1 \mathrm{M} \mathrm{KOH}$ (b). The curve for Pt/C was also measured for comparison. Catalyst loadings of FeNC-1 and $\mathrm{Pt} / \mathrm{C}$ were $800 \mu \mathrm{g}_{\mathrm{FeNC}-1} \mathrm{~cm}^{-2}$ and $20 \mu \mathrm{g}_{\mathrm{Pt}} \mathrm{cm}^{-2}$, respectively. 

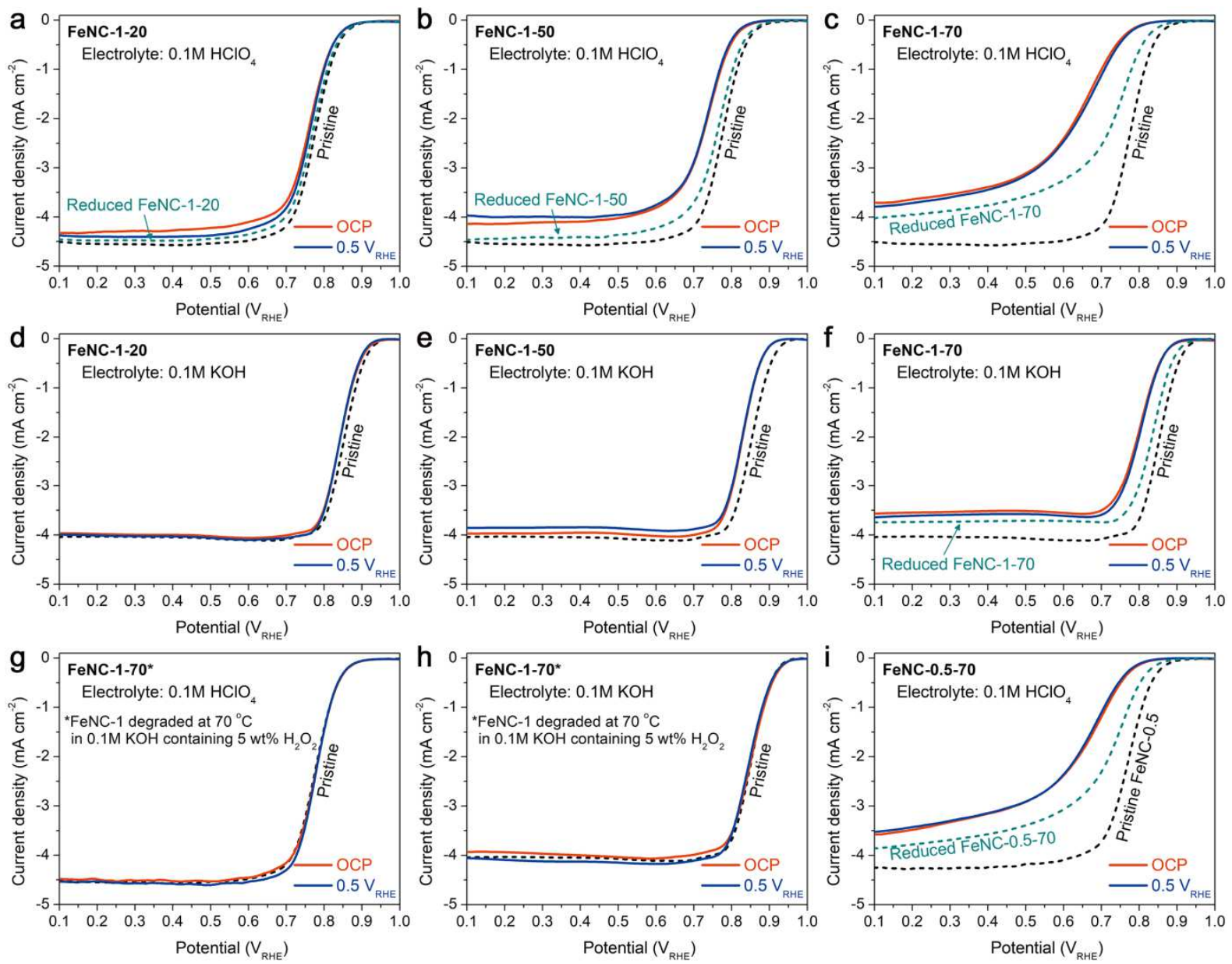

Figure S3 | ORR activity decrease following acidic $\mathrm{H}_{2} \mathrm{O}_{2}$-treatment and unmodified activity following alkaline $\mathrm{H}_{2} \mathrm{O}_{2}$-treatment. ORR polarization curves before and after acidic $\mathrm{H}_{2} \mathrm{O}_{2}$-treatment, measured in a-c, $\mathrm{O}_{2}$-saturated $0.1 \mathrm{M} \mathrm{HClO}_{4}$ and d-f, $\mathrm{O}_{2}$-saturated $0.1 \mathrm{M} \mathrm{KOH}$. The $\mathrm{H}_{2} \mathrm{O}_{2}$-treatment was carried out at $20(\mathbf{a}, \mathbf{d}), 50(\mathbf{b}, \mathbf{e})$ or $70{ }^{\circ} \mathrm{C}(\mathbf{c}, \mathbf{f})$ in $5 \mathrm{wt} \% \mathrm{H}_{2} \mathrm{O}_{2}$ in 0.1 $\mathrm{M} \mathrm{HClO}_{4}$, with the potential fixed either at $0.5 \mathrm{~V}_{\mathrm{RHE}}$ or open circuit potential (ca. $\left.0.84 \mathrm{~V}_{\mathrm{RHE}}\right)$. g, h, ORR polarization curves before and after alkaline $\mathrm{H}_{2} \mathrm{O}_{2}$-treatment, measured in $\mathrm{O}_{2}$ saturated $0.1 \mathrm{M} \mathrm{HClO}_{4}(\mathbf{g})$ and $\mathrm{O}_{2}$-saturated $0.1 \mathrm{M} \mathrm{KOH}(\mathbf{h})$. The $\mathrm{H}_{2} \mathrm{O}_{2}$-treatment was carried out at $70{ }^{\circ} \mathrm{C}$ in $5 \mathrm{wt} \% \mathrm{H}_{2} \mathrm{O}_{2}$ in $0.1 \mathrm{M} \mathrm{KOH}$, with the electrode potential fixed either at $0.5 \mathrm{~V}_{\mathrm{RHE}}$ or open circuit potential ( $c a .0 .94 \mathrm{~V}_{\mathrm{RHE}}$ ). i, ORR polarization curves of FeNC-0.5 before and after acidic $\mathrm{H}_{2} \mathrm{O}_{2}$-treatment at $70{ }^{\circ} \mathrm{C}$, measured in $\mathrm{O}_{2}$-saturated $0.1 \mathrm{M} \mathrm{HClO}_{4}$. FeNC-0.5 was 
prepared identically to FeNC-1, except for the halved Fe precursor content, resulting in $100 \%$ Fe being present as $\mathrm{FeN}_{\mathrm{x}} \mathrm{C}_{\mathrm{y}}$ moieties after pyrolysis ${ }^{7}$. FeNC-0.5 and FeNC-1 respond similarly to $\mathrm{H}_{2} \mathrm{O}_{2}$-treatment (compare figures $\mathrm{i}$ and c). Polarization curves for FeNC-1-70 and FeNC0.5-70 after electrochemical reduction in $0.5 \mathrm{M} \mathrm{NaCl}$ are also shown in $\mathbf{c}, \mathbf{f}, \mathbf{i}$ (green dotted curve). The polarization curve for pristine FeNC-1 is shown in all graphs (black dotted curve). 


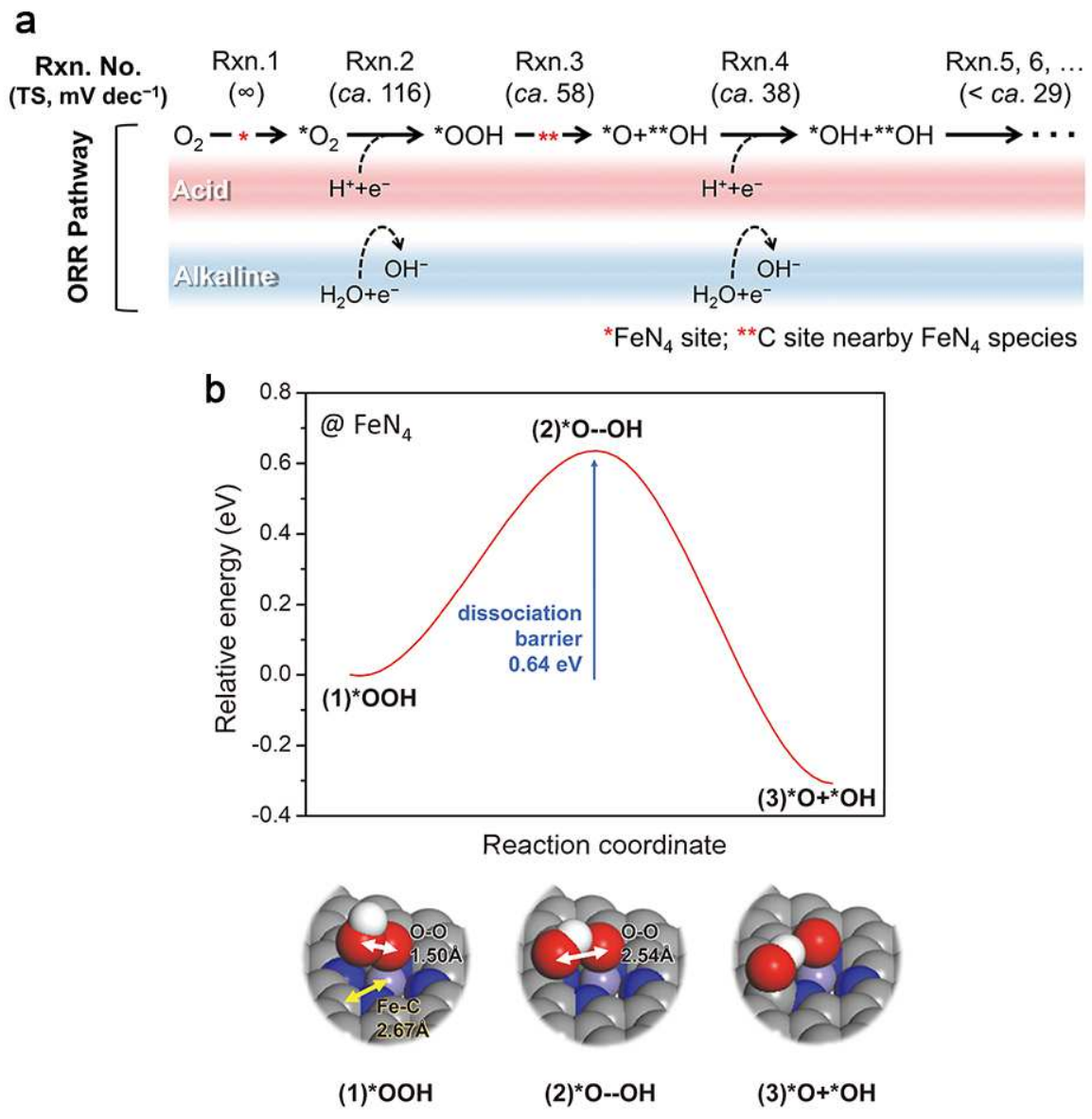

Figure S4 | ORR pathway and Tafel slope (TS). a, Direct $4 \mathrm{e}^{-}$ORR mechanism of Fe-N-C catalysts having two adsorption sites $\left(\mathrm{FeN}_{4} \text { site and } \mathrm{C} \text { site nearby the } \mathrm{FeN}_{4} \text { moiety }\right)^{16}$. The TSvalues were calculated applying $\mathrm{TS}=R T \ln 10 / \alpha F$, where $R, T, \alpha$ and $F$ are the gas constant, temperature, charge-transfer coefficient (a composite term derived from the overall multielectronic reaction and the RDS position in the sequence of elementary steps $^{17}$ ) and Faraday constant, respectively. TS-values are predicted from first-principles to be $c a$. 116 and $58 \mathrm{mV} \mathrm{dec}^{-1}$ when the first-electron transfer step (Rxn. 2) and the consecutive dissociation step (Rxn. 3) are the RDS, respectively. Upon extensively weakened $\mathrm{O}_{2}$ binding (highly oxidized surface), the first-electron transfer could become the RDS. The steps after the second-electron transfer (Rxn. 4) are not shown since they are not rate-determining (the predicted TS-value would otherwise be $<c a .29 \mathrm{mV} \mathrm{dec}{ }^{-1}$, much lower than experimental values of $63-110 \mathrm{mV}$ 
$\mathrm{dec}^{-1}$ in $\mathrm{pH}$ 1). b, Based on our DFT calculation of the RDS (*OOH dissociation, Rxn. 3) on $\mathrm{Fe}-\mathrm{N}-\mathrm{C}$ catalysts, the distance between a central $\mathrm{Fe}$ ion and the nearest carbon atom is $2.67 \AA$ (comparable to the Pt-Pt distance of $2.8 \AA$ on the $\mathrm{Pt}(111)$ surface $^{18}$ ), where O-O bond dissociation can occur with a moderate activation energy barrier of $0.64 \mathrm{eV}$. 


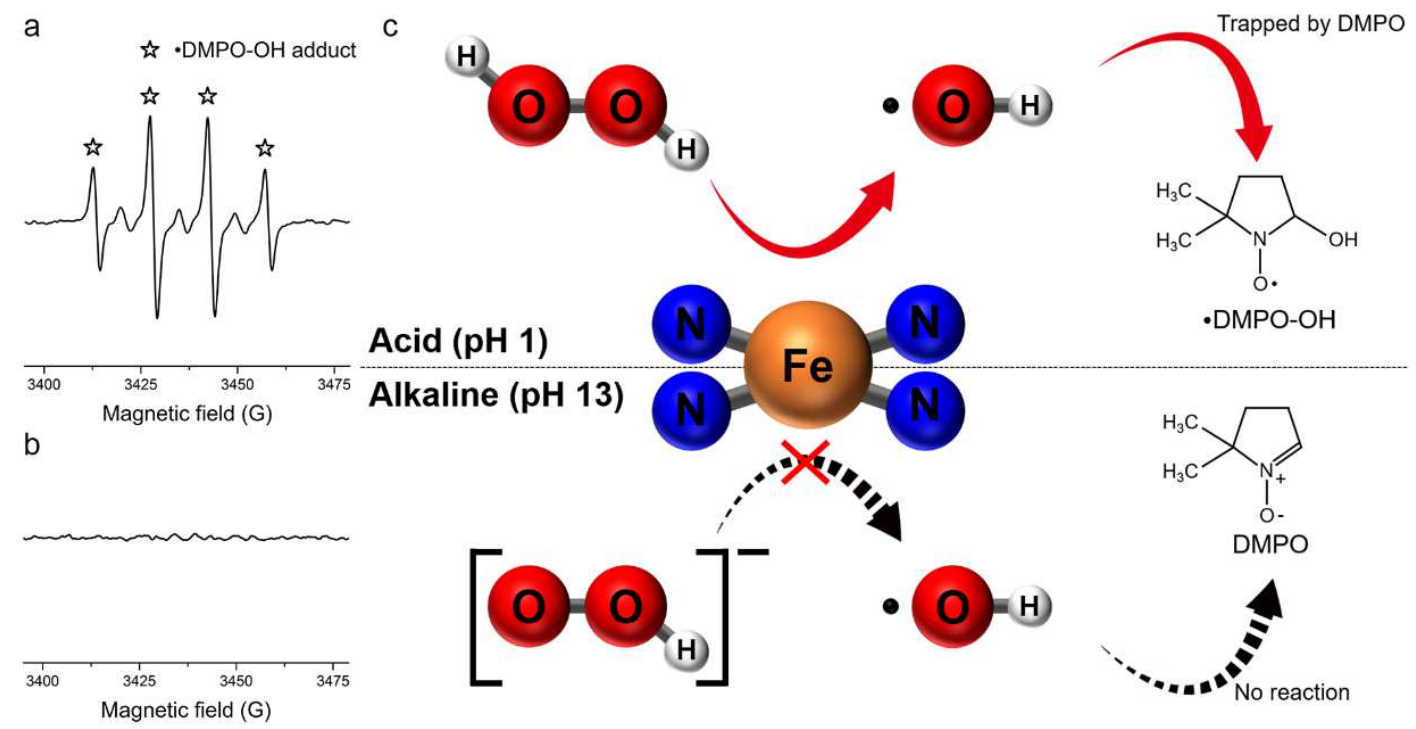

Figure S5 | Spin-trap experiment revealing the formation of ROS during peroxide treatment of Fe-N-C in acidic conditions. a-b, EPR spectra of filtered solution aliquots after 5 min $\mathrm{H}_{2} \mathrm{O}_{2}$-treatment at room temperature of FeNC-0.5 in a) $0.1 \mathrm{M} \mathrm{HClO}_{4}$ or b) $0.1 \mathrm{M} \mathrm{KOH}$ electrolytes. The main quartet signal from -DMPO-OH was indicated by a star symbol. c, Scheme of EPR measurement representing the formation of $\cdot \mathrm{DMPO}-\mathrm{OH}$ spin adduct in acidic but not in alkaline electrolyte. 


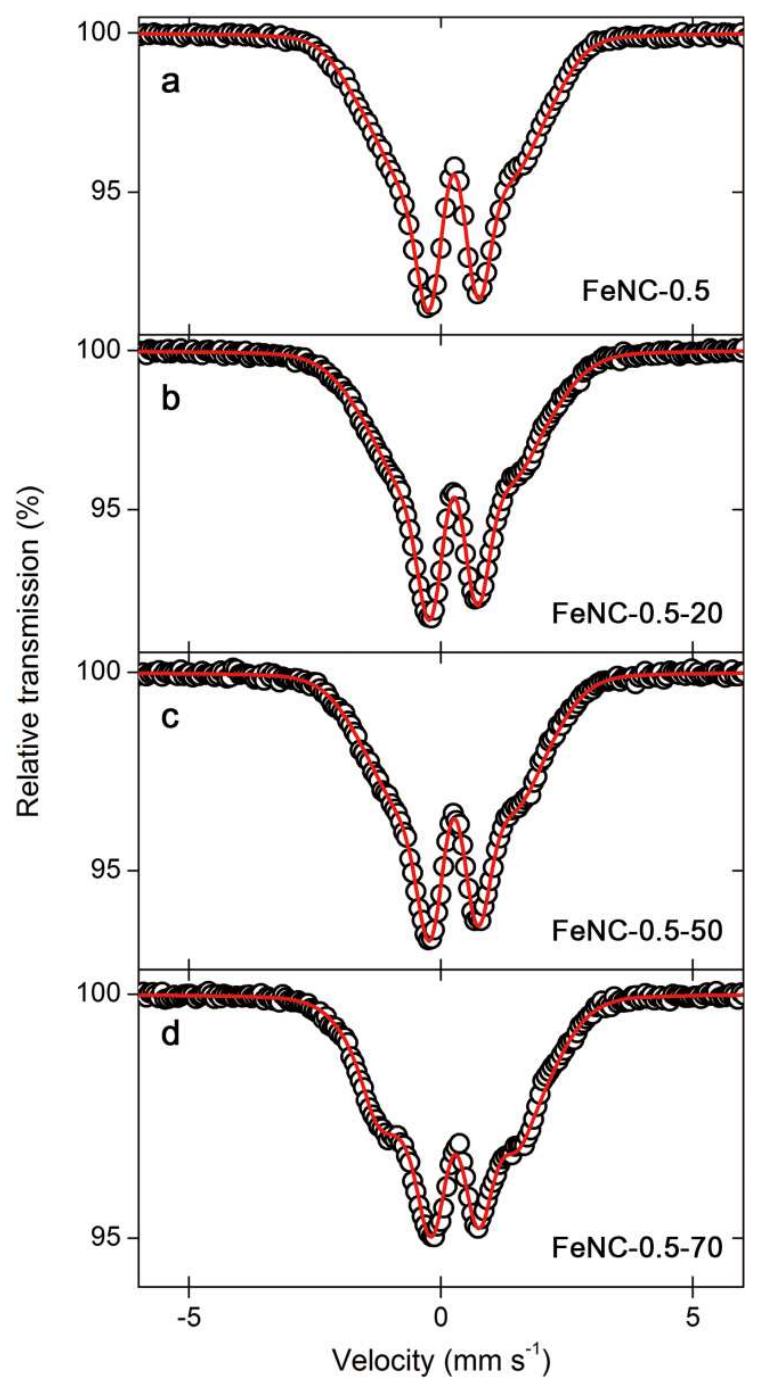

Figure S6 | Room temperature ${ }^{57}$ Fe Mössbauer spectra of FeNC-0.5 before and after acidic $\mathrm{H}_{2} \mathrm{O}_{2}$-treatment. a, Pristine FeNC-0.5, and after treatment in $5 \mathrm{wt} \% \mathrm{H}_{2} \mathrm{O}_{2}$ in $0.1 \mathrm{M}$ $\mathrm{HClO}_{4}$ at b, $20{ }^{\circ} \mathrm{C}, \mathbf{c}, 50{ }^{\circ} \mathrm{C}$ and $\mathbf{d}, 70{ }^{\circ} \mathrm{C}$. The fitting (red curves) was carried out with three Gaussian distributions of the electric quadrupole interaction. The analysis was performed on FeNC-0.5 (halved Fe content relative to FeNC-1) to avoid the singlet $(\gamma-\mathrm{Fe})$ and sextet $(\alpha-\mathrm{Fe})$, both present in pristine FeNC-1 (Fig. S1b), and that would have impeded the QS-distribution analysis of the subtle changes occurring to the doublet components. 

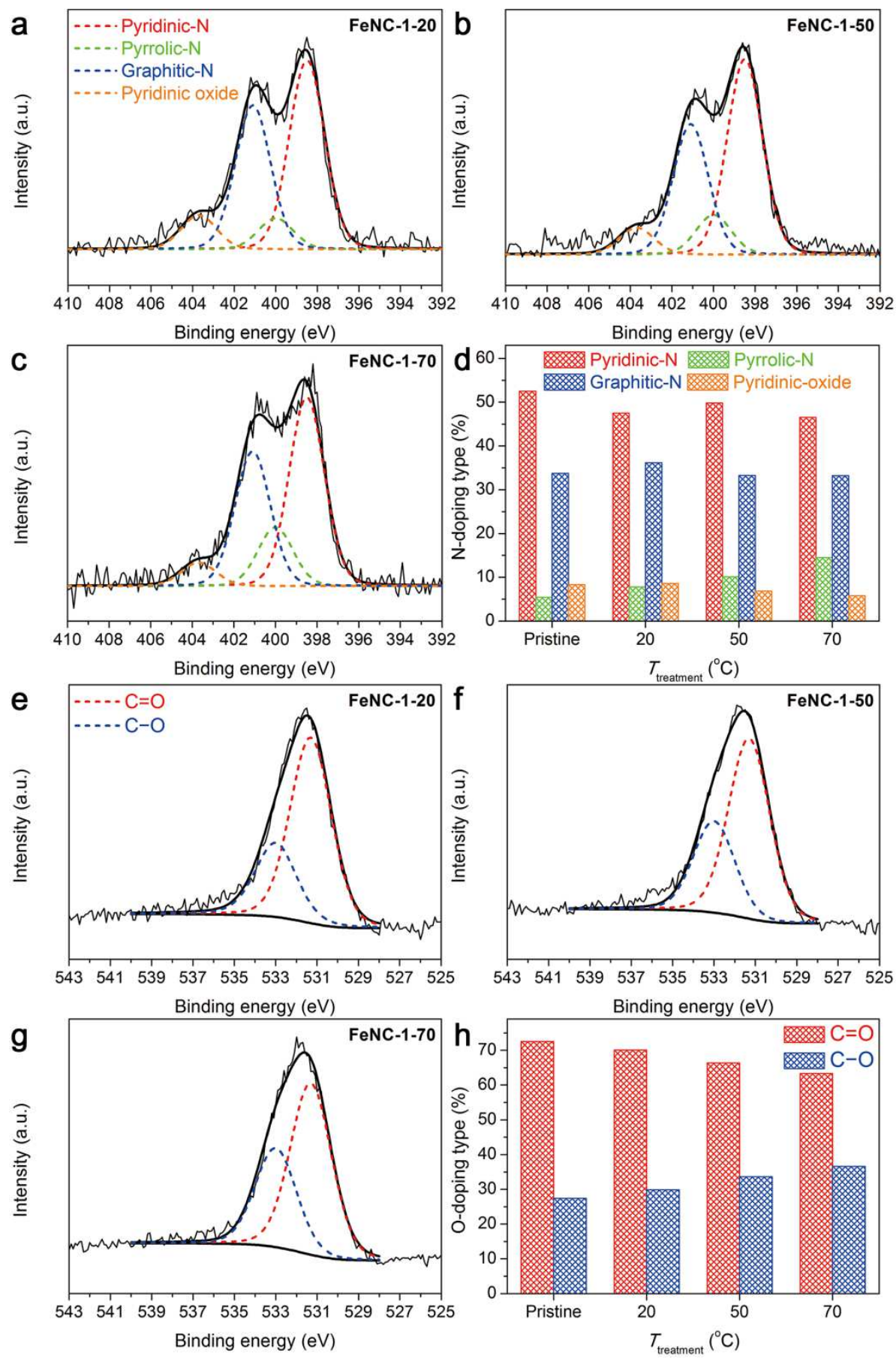

Figure S7 | XPS analyses of FeNC-1 after acidic $\mathrm{H}_{2} \mathrm{O}_{2}$-treatments. a-c, XPS- $\mathrm{N}_{1 \mathrm{~s}}$ signal and fitting results of FeNC-1 before and after treatment in $5 \mathrm{wt} \% \mathrm{H}_{2} \mathrm{O}_{2}$ in $0.1 \mathrm{M} \mathrm{HClO}_{4}$ at $20{ }^{\circ} \mathrm{C}$ (a), $50{ }^{\circ} \mathrm{C}$ (b) and $70{ }^{\circ} \mathrm{C}$ (c). The fitting was carried out with pyridinic-N (398.5 eV, red), pyrrolic-N (400.1 eV, green), graphitic-N (401.1 eV, blue) and pyridinic-oxide (403.7 eV, 
orange) peaks ${ }^{4}$. d, Ratio of N-doping types before and after acidic $\mathrm{H}_{2} \mathrm{O}_{2}$-treatment. e-g, XPS$\mathrm{O}_{1 \text { s }}$ signal and fitting results of FeNC-1 before and after $\mathrm{H}_{2} \mathrm{O}_{2}$-treatment at $20{ }^{\circ} \mathrm{C}(\mathbf{e}), 50{ }^{\circ} \mathrm{C}(\mathbf{f})$ and $70{ }^{\circ} \mathrm{C}(\mathbf{g})$. The fitting was carried out with $\mathrm{C}=\mathrm{O}(531.2 \mathrm{eV}$; carbonyl and carboxyl $)$ and $\mathrm{C}$ $\mathrm{O}$ (533.0 eV; epoxy and hydroxyl) peaks ${ }^{5,6} . \mathbf{h}$, Ratio of O-doping types before and after acidic $\mathrm{H}_{2} \mathrm{O}_{2}$-treatment. 
a $\mathrm{FeN}_{4}$

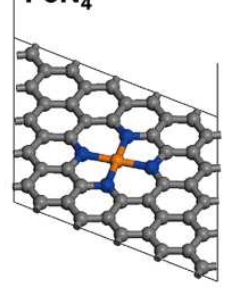

$\mathrm{FeN}_{4}-(\mathrm{O} O \mathrm{OH})_{n}-($ near|far $)$
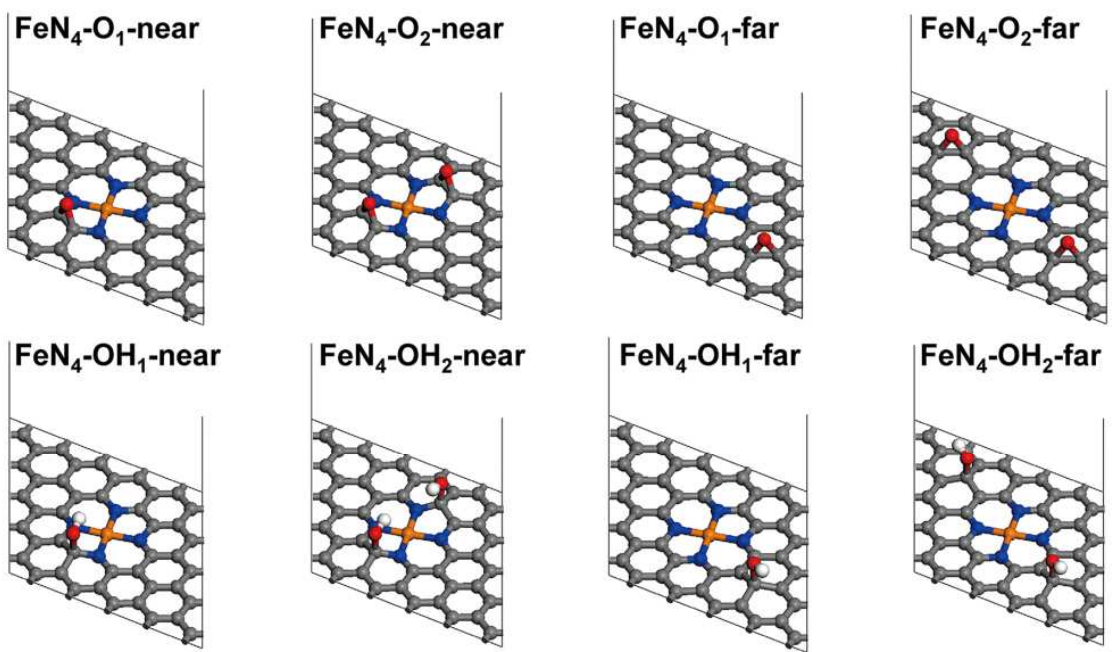

b

\begin{tabular}{ccccc}
\hline Active site models & ${ }^{*} \mathrm{O}_{2}(\mathrm{eV})$ & ${ }^{*} \mathrm{OOH}(\mathrm{eV})$ & ${ }^{*} \mathrm{O}(\mathrm{eV})$ & ${ }^{*} \mathrm{OH}(\mathrm{eV})$ \\
\hline $\mathrm{FeN}$ & -0.59 & -1.37 & -4.09 & -2.59 \\
$\mathrm{FeN}_{4}-\mathrm{O}_{1}$-far & -0.49 & -1.33 & -4.04 & -2.55 \\
$\mathrm{FeN}_{4}-\mathrm{O}_{2}$-far & -0.44 & -1.30 & -3.99 & -2.51 \\
$\mathrm{FeN}_{4}-\mathrm{O}_{1}$-near & -0.30 & -1.07 & -3.72 & -2.26 \\
$\mathrm{FeN}_{4}-\mathrm{O}_{2}$-near & +0.33 & -0.43 & -3.22 & -1.99 \\
$\mathrm{FeN}_{4}-\mathrm{OH}_{1}$-far & -0.50 & -1.30 & -4.02 & -2.48 \\
$\mathrm{FeN}_{4}-\mathrm{OH}_{2}$-far & -0.43 & -1.28 & -4.00 & -2.44 \\
$\mathrm{FeN}_{4}-\mathrm{OH}_{1}$-near & -0.54 & -1.33 & $(-4.15)$ & $(-2.80)$ \\
$\mathrm{FeN}_{4}-\mathrm{OH}_{2}$-near & -0.46 & -1.26 & $(-4.16)$ & $(-2.60)$ \\
\hline
\end{tabular}

Figure S8 | Atomistic models of $\mathrm{FeN}_{4}$ active sites covalently integrated in graphene sheets that were utilized for DFT calculations. a, The models are labeled $\mathrm{FeN}_{4}-(\mathrm{O} / \mathrm{OH})_{\mathrm{n}}-(\mathrm{near} / \mathrm{far})$, where $\mathrm{O}$ stands for epoxy group, $\mathrm{OH}$ for hydroxyl group, the subscript " $\mathrm{n}$ " stands for the number of oxygen-functional groups, and "near" or "far" stands for the relative distance between the Fe active center and oxygen-functional groups. b. Binding energies of reaction intermediates $\left(\mathrm{O}_{2}, \mathrm{OOH}, \mathrm{O}\right.$ and $\left.\mathrm{OH}\right)$ on various $\mathrm{FeN}_{4}$ models. DFT result shows that the binding energies of reaction intermediates decrease with increasing extent of carbon surface 
oxidation, except for the four cases indicated with brackets, where the existence of hydrogen bonding between surface hydroxyl group and $* \mathrm{O}$ or $* \mathrm{OH}$ stabilizes reaction intermediates. The more negative is the value, the stronger is the binding. 


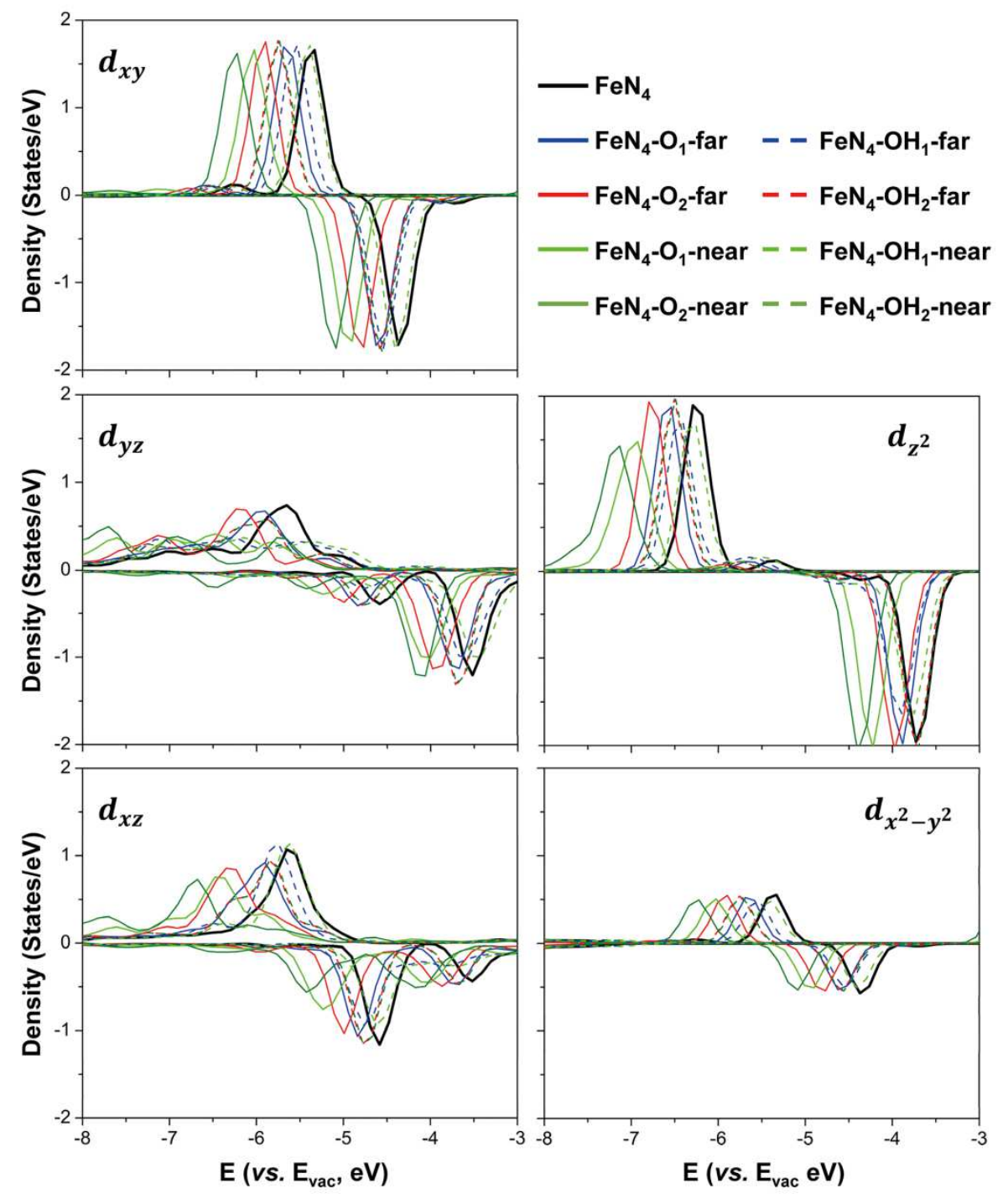

Figure S9 | Fe $d$-orbital locations aligned with respect to the vacuum level $\left(E_{\text {vac }}\right)$. Energy eigenvalues of Fe $d$-orbitals are blue-shifted as the oxygen-functional groups are introduced into the carbon support. This decreases the hardness and thereby the binding strength of oxygen reaction intermediates to the Fe-center, i.e. oxophilicity. 

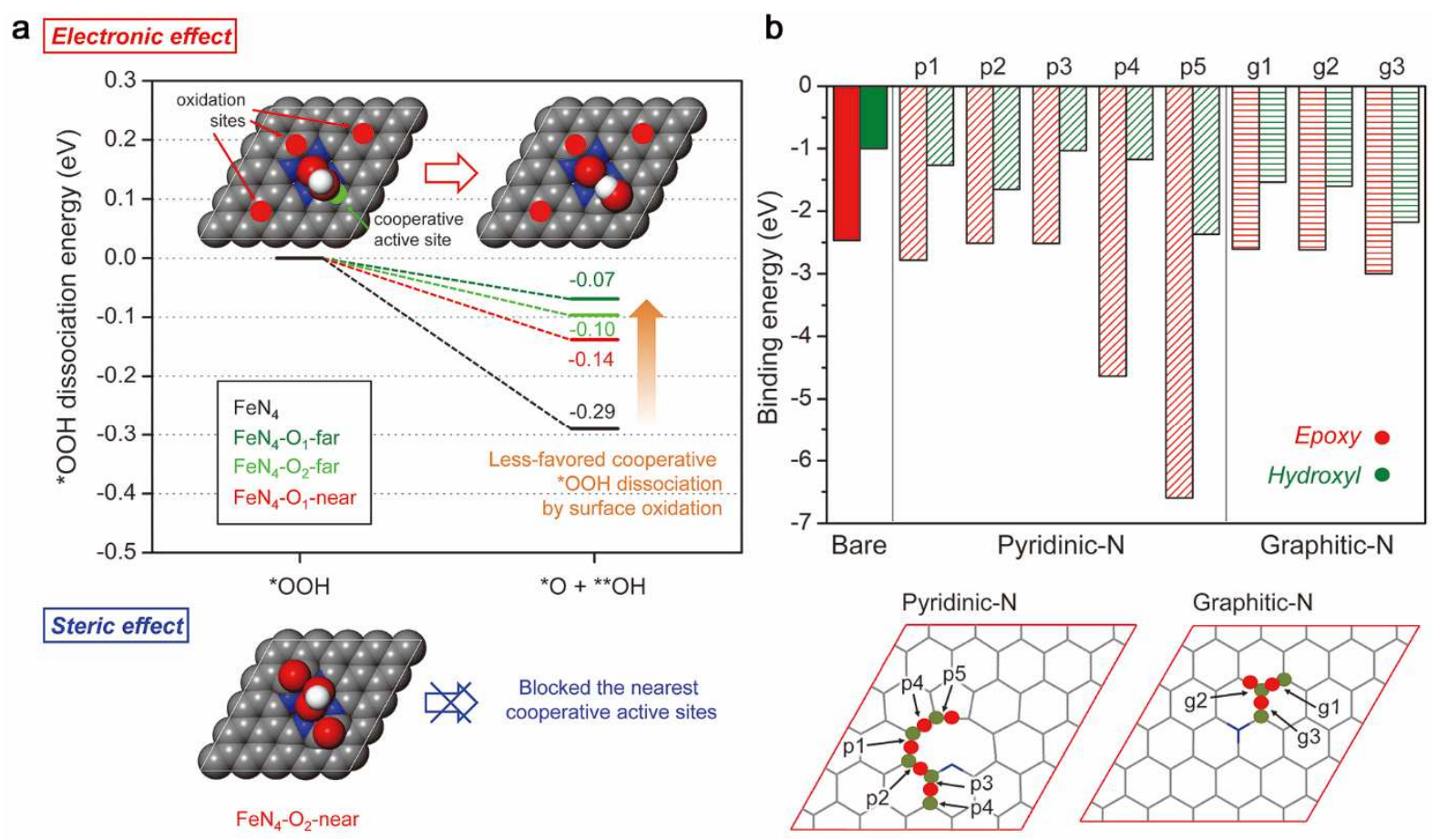

Figure S10 | Retardation of *OOH dissociation pathway by surface oxidation of carbon and enhanced oxygen affinity near $\mathbf{N}$-doped sites. a, The ${ }^{*} \mathrm{OOH}$ dissociation process becomes less favored due to electronic and steric effects as epoxy groups are introduced onto the graphene support near the $\mathrm{FeN}_{4}$ center, and especially at the nearest carbon center. $\mathbf{b}$, The calculated binding energies of oxygen-groups to carbon sites situated nearby $\mathrm{N}$-groups (a more negative value means a stronger binding). Compared to the pristine graphene surface showing binding strengths of 2.46 and $0.99 \mathrm{eV}$ for $\mathrm{O}$ and $\mathrm{OH}$, respectively, the carbon sites at the fivemembered ring near the pyridinic-N site show enhanced binding strength, up to 6.59 and 2.37 $\mathrm{eV}$ for $\mathrm{O}$ and $\mathrm{OH}$ (at $\mathrm{p} 5$ site), respectively. 
Table S1 | Mössbauer and EXAFS fitting results of FeNC-1.

\begin{tabular}{|c|c|c|c|c|c|c|}
\hline \multirow{5}{*}{$\begin{array}{l}\text { Mössbauer } \\
\text { fitting } \\
(\text { FeNC-1) }\end{array}$} & Component & $\begin{array}{c}\text { Relative } \\
\text { adsorption } \\
\text { area }(\%)\end{array}$ & $\begin{array}{l}\text { Relative Fe } \\
\text { content (\%) }\end{array}$ & $\begin{array}{c}\mathrm{IS}^{\mathrm{a}} \\
\left(\mathrm{mm} \mathrm{s}^{-1}\right)\end{array}$ & $\begin{array}{c}\mathrm{QS}^{\mathrm{b}} \\
\left(\mathrm{mm} \mathrm{s}^{-1}\right)\end{array}$ & $\begin{array}{c}\mathrm{LW}^{\mathrm{c}} \\
\left(\mathrm{mm} \mathrm{s}^{-1}\right)\end{array}$ \\
\hline & $\begin{array}{c}\mathrm{Fe}^{\mathrm{II}} \mathrm{N}_{4} / \mathrm{C}-\mathrm{LS} \\
\text { (D1) }\end{array}$ & 58 & 62 & 0.38 & 1.10 & 0.78 \\
\hline & $\begin{array}{c}\mathrm{Fe}^{\mathrm{II}} \mathrm{N}_{4} / \mathrm{C}-\mathrm{MS} \\
\text { (D2) }\end{array}$ & 34 & 33 & 0.43 & 2.65 & 1.45 \\
\hline & $\begin{array}{c}\alpha-\mathrm{Fe} \\
\text { (Sextet 1) }\end{array}$ & 3 & 2 & -0.02 & - & 0.35 \\
\hline & $\begin{array}{c}\gamma-\mathrm{Fe} \\
\text { (Singlet) }\end{array}$ & 5 & 3 & -0.10 & - & 0.42 \\
\hline \multirow{13}{*}{$\begin{array}{l}\text { EXAFS } \\
\text { fitting }^{\text {d }}\end{array}$} & Catalyst & Shell & $\mathrm{CN}^{\mathrm{e}}$ & $R(\AA)^{f}$ & $\Delta \sigma^{2}\left(\AA^{2}\right)^{g}$ & R-factor \\
\hline & \multirow{3}{*}{ FeNC-1 } & $\mathrm{Fe}-\mathrm{N}^{\mathrm{h}}$ & 4 & $1.97(1)$ & $0.007(2)$ & \multirow{3}{*}{0.0019} \\
\hline & & $\mathrm{Fe}-\mathrm{O}^{\mathrm{h}}$ & 1 & $2.09(2)$ & $0.003(2)$ & \\
\hline & & $\mathrm{Fe}-\mathrm{Fe}^{\mathrm{i}}$ & $0.6(3)$ & $2.49(1)$ & $0.011(8)$ & \\
\hline & \multirow{3}{*}{ FeNC-1-20 } & $\mathrm{Fe}-\mathrm{N}$ & 4 & $1.98(2)$ & $0.007(1)$ & \multirow{3}{*}{0.0075} \\
\hline & & $\mathrm{Fe}-\mathrm{O}$ & 1 & $2.10(4)$ & $0.003(2)$ & \\
\hline & & $\mathrm{Fe}-\mathrm{Fe}$ & $0.5(3)$ & $2.49(2)$ & $0.009(8)$ & \\
\hline & \multirow{3}{*}{ FeNC-1-50 } & $\mathrm{Fe}-\mathrm{N}$ & 4 & $1.98(2)$ & $0.007(2)$ & \multirow{3}{*}{0.0087} \\
\hline & & $\mathrm{Fe}-\mathrm{O}$ & 1 & $2.08(4)$ & $0.003(2)$ & \\
\hline & & $\mathrm{Fe}-\mathrm{Fe}$ & $0.6(5)$ & $2.49(2)$ & $0.010(8)$ & \\
\hline & \multirow{3}{*}{ FeNC-1-70 } & $\mathrm{Fe}-\mathrm{N}$ & 4 & $1.98(2)$ & $0.007(2)$ & \multirow{3}{*}{0.0087} \\
\hline & & $\mathrm{Fe}-\mathrm{O}$ & 1 & $2.10(5)$ & $0.003(2)$ & \\
\hline & & $\mathrm{Fe}-\mathrm{Fe}$ & $0.5(4)$ & $2.49(3)$ & $0.008(8)$ & \\
\hline
\end{tabular}

a Isomer shift. ${ }^{\mathrm{b}}$ Quadrupole splitting. ${ }^{\mathrm{c}}$ Line width. ${ }^{\mathrm{d}}$ Errors in the fitting results were noted in parentheses $\left(\Delta k=2-9 \AA^{-1}\right)$. ${ }^{\mathrm{e}}$ Coordination number. ${ }^{\mathrm{f}}$ Distance between absorber and 
backscattering atoms. ${ }^{\mathrm{g}}$ Debye-Waller factor. ${ }^{\mathrm{h}} \mathrm{CN}_{\mathrm{Fe}-\mathrm{N}}$ and $\mathrm{CN}_{\mathrm{Fe}-\mathrm{O}}$ were fixed to 4 and 1 , respectively, on the basis of i) our previous XANES-EXAFS structure identification of $\mathrm{FeN}_{\mathrm{x}} \mathrm{C}_{\mathrm{y}}$ moieties $^{7}$ and ii) Mössbauer spectroscopy showing that $95 \% \mathrm{Fe}$ in FeNC-1 is present as $\mathrm{FeN}_{4}$ moieties. The EXAFS fitting was carried out with $\mathrm{Fe}-\mathrm{N}, \mathrm{Fe}-\mathrm{O}$ and $\mathrm{Fe}-\mathrm{Fe}$ bond distances and $\mathrm{CN}_{\mathrm{Fe}-\mathrm{Fe}}$ as variables. ${ }^{\mathrm{i}} \mathrm{CN}_{\mathrm{Fe}-\mathrm{Fe}}$ of 0.6 corresponds well with the value of 0.64 which is calculated for FeNC-1 from the knowledge of i) the relative Fe-content of $\alpha$-Fe and $\gamma$-Fe determined by Mössbauer spectroscopy and ii) known $\mathrm{CN}_{\mathrm{Fe}-\mathrm{Fe}}$ in pure $\alpha$-Fe and $\gamma$-Fe. However, it cannot be excluded that a small fraction of the Fe-Fe EXAFS signal for FeNC-1 originates from binuclear $\mathrm{Fe}_{2} \mathrm{~N}_{\mathrm{x}} \mathrm{C}_{\mathrm{y}}$ sites that were recently suggested by Holby et al. ${ }^{10,11}$ (see also Fig. S1f and its caption). 


\section{References}

$1 \mathrm{Wu}, \mathrm{G}$. et al. Performance durability of polyaniline-derived non-precious cathod e catalysts. ECS Trans. 25, 1299-1311 (2009).

2 Ravel, B. \& Newville, M. ATHENA, ARTEMIS, HEPHAESTUS: data analysis for X-ray absorption spectroscopy using IFEFFIT. J. Synchrotron Radiat. 12, 537-541 (2005).

3 Du, H. C. A nonlinear filtering algorithm for denoising HR(S)TEM micrograph s. Ultramicroscopy 151, 62-67 (2015).

4 Guo, D. et al. Active sites of nitrogen-doped carbon materials for oxygen redu ction reaction clarified using model catalysts. Science 351, 361-365 (2016).

5 Zhang, J. et al. Surface-modified carbon nanotubes catalyze oxidative dehydrog enation of n-butane. Science 322, 73-77 (2008).

6 Bagri, A. et al. Structural evolution during the reduction of chemically derived graphene oxide. Nat. Chem. 2, 581-587 (2010).

7 Zitolo, A. et al. Identification of catalytic sites for oxygen reduction in iron- a nd nitrogen-doped graphene materials. Nat. Mater. 14, 937-942 (2015).

8 Herranz, J. et al. Unveiling N-protonation and anion-binding effects on $\mathrm{Fe} / \mathrm{N} / \mathrm{C}$ catalysts for $\mathrm{O}_{2}$ reduction in proton-exchange-membrane fuel cells. J. Phys. Ch em. C 115, 16087-16097 (2011).

9 Guo, H. L., Wang, X. F., Qian, Q. Y., Wang, F. B. \& Xia, X. H. A green a pproach to the synthesis of graphene nanosheets. ACS Nano 3, 2653-2659 (200 9).

10 Toh, S. Y., Loh, K. S., Kamarudin, S. K. \& Daud, W. R. W. Graphene produ 
ction via electrochemical reduction of graphene oxide: Synthesis and characteris ation. Chem. Eng. J. 251, 422-434 (2014).

11 Kresse, G. \& Furthmüller, J. Efficiency of ab-initio total energy calculations fo r metals and semiconductors using a plane-wave basis set. Comp. Mater. Sci. 6 , 15-50 (1996).

12 Hammer, B., Hansen, L. B. \& Nørskov, J. K. Improved adsorption energetics within density-functional theory using revised Perdew-Burke-Ernzerhof functional s. Phys. Rev. B 59, 7413-7421 (1999).

13 Fishman, M., Zhuang, H. L., Mathew, K., Dirschka, W. \& Hennig, R. G. Acc uracy of exchange-correlation functionals and effect of solvation on the surface energy of copper. Phys. Rev. B 87, 245402 (2013).

14 Holby, E. F. \& Taylor, C. D. Activity of N-coordinated multi-metal-atom activ e site structures for Pt-free oxygen reduction reaction catalysis: Role of $* \mathrm{OH}$ li gands. Sci. Rep. 5, 9286 (2015).

15 Holby, E. F., Wu, G., Zelenay, P. \& Taylor, C. D. Structure of Fe- $\mathrm{N}_{\mathrm{x}}-\mathrm{C}$ defec ts in oxygen reduction reaction catalysts from first-principles modeling. J. Phys. Chem. C 118, 14388-14393 (2014).

16 Kattel, S. \& Wang, G. Reaction pathway for oxygen reduction on $\mathrm{FeN}_{4}$ embed ded graphene. J. Phys. Chem. Lett. 5, 452-456 (2014).

17 Fletcher, S. Tafel slopes from first principles. J. Solid State Electrochem. 13, 5 37-549 (2009).

18 Duan, Z. \& Wang, G. A first principles study of oxygen reduction reaction on a $\operatorname{Pt}(111)$ surface modified by a subsurface transition metal $\mathrm{M}(\mathrm{M}=\mathrm{Ni}, \mathrm{Co}$, 
or Fe). Phys. Chem. Chem. Phys. 13, 20178-20187 (2011). 
